\title{
Harmonious and Obsessive Involvement, Self-Esteem, and Well-Being. A Longitudinal Study on MMORPG Players
}

\author{
Federica Sibilla, Alessandro Musetti, \& Tiziana Mancini \\ Department of Humanities, Social Sciences and Cultural Industries, University of Parma, Parma, Italy
}

\begin{abstract}
Starting from the dualistic model of passion by Vallerand and colleagues (2003), this study aimed to identify "obsessive" and "harmonious" involvements in MMORPGs and to verify their relationships with players' self-esteem and well-being. An international sample of 147 MMORPG players participated in a longitudinal design filling out for 3 times an online questionnaire measuring game involvement (in terms of Internet Gaming Disorder [IGD] symptoms, time spent playing the video game, sense of presence while playing, and avatar identification), global self-esteem, and well-being (i.e., meaningful life, engaged life, and pleasant life). Results supported the presence of these two different types of involvement: Obsessive involvement, characterized by a close association between IGD symptoms and playing time; Harmonious involvement, characterized by a close association between presence, avatar identification, and IGD symptoms. Cross-lagged effects showed that, over time, low self-esteem and low meaningful life predicted obsessive involvement, which in turn predicted engaged life. The present study contributes to a better understanding of the effects between video games use and the users' self-esteem and wellbeing. Furthermore, it contributes to the theoretical debate about problematic involvement in videogames, also providing some indications about problematic gaming assessment and prevention.
\end{abstract}

Keywords: Game involvement; problematic gaming; Internet gaming disorder; well-being; self-esteem; MMORPGs

\section{Introduction}

In today's societies, pervasive Internet use has become part of people's daily lives (Musetti \& Corsano, 2018) and online video gaming is one of the most popular and widespread forms of leisure activity (Statista, 2020; Wang et al., 2008). Playing video games has been associated with positive and beneficial outcomes including cognitive, motivational, emotional, social (Granic et al., 2014; Johnson et al., 2013), educational (Braghirolli et al., 2016; Dobrescu et al., 2015), and therapeutic (Griffiths, 2004, 2019) benefits. On the other hand, a vast amount of research has provided evidence for detrimental and harmful effects of excessive and uncontrolled gaming use in a minority of video game players (Burleigh et al., 2019; Männikkö et al., 2017). As a consequence, the American Psychiatric Association (APA) included Internet Gaming Disorder (IGD) in the fifth revision of the Diagnostic and Statistical Manual (DSM-5) of mental disorders in the research appendix (Section III) as a condition requiring further study (APA, 2013, p. 796). Specifically, the clinical diagnosis of IGD comprises a persistent and recurrent pattern of playing video games, leading to a clinically significant impairment or distress over a period of at least 12 months, as manifested by endorsing five (or more) of nine proposed criteria (i.e., preoccupation, withdrawal, tolerance, loss of control, loss of interest, continued overuse, deceiving, escape from negative feelings, functional impairment). Nevertheless, many concerns have been raised about the threshold-based DSM-5 approach to gaming disorder diagnosis (Aarseth et al., 2017; Billieux, Schimmenti, et al., 2015; Jeong et al., 2018; Jo et al., 2019; Van Rooij et al., 2018). Thus, several studies showed that a significant number of game players display symptoms 
of IGD without developing a disorder (e.g., Billieux, Thorens et al., 2015; Musetti et al., 2019). In fact, empirical evidence (Brunborg et al., 2013; Charlton, 2002; Charlton \& Danforth, 2007, 2010; Lehenbauer-Baum et al., 2015; Lehenbauer-Baum \& Fohringer, 2015) supported the distinction between core (i.e., behavioral salience, conflict, withdrawal, and relapse) and peripheral (i.e., cognitive salience, euphoria, and tolerance) criteria, where the former define a pathological addiction and the latter define a non-pathological engagement. Consistently, Deleuze and colleagues (2017) found that the cognitive salience criterion was endorsed by $77.3 \%$ of their sample of regular video game players. A step further was taken by Billieux et al. (2019), who highlighted the role of the psychological processes associated with gaming experience in distinguishing between different types of involvement in video games. The authors distinguished between high involvement (a passion), which is associated with nonpsychopathological underlying processes (e.g., social-related motives), and pathological involvement (an addiction), which is associated to problematic patterns of playing (e.g., loss of control over gaming). Consistently, the most recent diagnostic proposals place great emphasis on functional impairment (World Health Organization, 2018). These are the reasons why a dimensional approach can provide a useful, complementary way to examine the psychological processes underlying addictive behaviors such as IGD (Morris \& Voon, 2016). Continuing along this line, the current study adopted a dimensional approach to investigate the different types of involvement in Massively Multiplayer Online Role-Playing Games (MMORPGs) - in terms of IGD symptoms and relevant video game usage variables - and their relationships with self-esteem and well-being in a sample of players.

\section{MMORPGs, Problematic Gaming, and Other Psychological Variables}

MMORPGs are a category of video games considered to be particularly risky, which is why the scientific community highly focused on their problematic use (Sibilla \& Mancini, 2018; Smyth, 2007). The scientific literature often evaluated problematic MMORPG use considering only IGD criteria (e.g., Kirby et al., 2014; Stetina et al., 2011) and overlooking other usage data. Nevertheless, the literature has pointed out that evaluating activities (e.g., internet gaming) with this criteria-based approach leads to the risk of overpathologizing conditions of high but nonpathological involvement, which is why a more processual approach is encouraged (Billieux, Schimmenti, et al., 2015). In fact, other relevant usage variables emerge from the literature on problematic MMORPGs use (Sibilla \& Mancini, 2018): time spent playing (Caplan et al., 2009; Peters \& Malesky, 2008; Smahel et al., 2008), avatar identification (Mancini et al., 2019; You et al., 2017), and perceived presence (Stavropoulos et al., 2019). Literature consistently found that a large amount of time spent playing video games is associated with negative outcomes (Allahverdipour et al., 2010; Colwell \& Payne, 2000; Durkin \& Barber, 2002; Fling et al., 1992; Funk \& Buchman, 1996; Przybylski et al., 2012; Wack \& Tantleff-Dunn, 2009), whereas presence and identification with the avatar are also associated with positive variables such as the flow (Ryan et al., 2006) or reduction of identity distress (Klimmt et al., 2009; Mancini \& Sibilla, 2017). This demonstrates that variables other than IGD symptoms should be taken into consideration to better understand the psychological quality of the gaming experience of problematic and non-problematic video game players.

\section{Psychological Experience of Problematic and Non-Problematic Video Game Players}

The dualistic model of passion by Vallerand and colleagues (2003) provides a sound theoretical framework to conceptualize the differences in the psychological experience of problematic and non-problematic video game players. The authors defined a passion as "a strong inclination toward an activity that people like, that they find important, and in which they invest time and energy" (р. 756). The authors identified two types of passion: "harmonious" and "obsessive". In the "harmonious passion" experience, a person carries out a meaningful activity on a voluntary basis and the activity is well integrated in the individual's self, does not interfere with other areas of life, makes the person feel good and effective, and promotes well-being and happiness. In contrast, in the "obsessive passion" experience, a person carries out a ritualistic-like and repetitive activity in reaction to unsatisfied self-needs, especially self-esteem. Consequently, the satisfaction of the individual self-needs is associated to the performance of the activity, which provides relief of the negative affect. Accordingly, the person carries out the activity in a rigid and compulsive manner, which engenders problematic use and compromises other areas of life. In this sense, obsessive involvement appears to be riskier than harmonious involvement for the person's well-being. 
In line with this perspective, this study aimed to extend these results, verifying how obsessive and harmonious involvements in MMORPG players related both with the individual's self - i.e., players' self-esteem - and with personal well-being.

\section{Obsessive and Harmonious Involvement, Self-Esteem, and Well-Being}

Przybylski and colleagues (2009) and Boyle and colleagues (2012) showed that well-being and self-needs satisfaction negatively associated with obsessive involvement and positively associated with harmonious involvement.

Consistently with the "obsessive passion" experience, some studies showed that problematic MMORPGs use positively associated with low levels of self-esteem (Billieux, Thorens et al., 2015; Kardefelt-Winther, 2014a; Leménager et al., 2013) or self-efficacy (Blinka \& Mikuška, 2014; Snodgrass et al., 2011, 2013). This low selfevaluation of problematic gamers is due to a greater discrepancy between the actual and ideal self of these players (Leménager et al., 2013). In fact, self-discrepancy (Higgins, 1987) favors depressive symptoms, which in turn pushes players to play MMORPGs as an escape from reality (Li et al., 2011) and to idealize their avatars (Bessière et al., 2007), both factors being positively associated with problematic gaming (Kardefelt-Winther, 2014b; Mancini et al., 2019). Consistently, some recent studies showed that - especially when some vulnerability factors (e.g., maladaptive personality traits or psychopathological symptoms) are present - using online video games as an escape and compensation from an offline life in which basic psychological needs are frustrated favored dysregulated and problematic gaming (Allen \& Anderson, 2018; Di Blasi et al., 2020; Mills et al., 2018; Przybylski \& Weinstein, 2019). Moreover, some studies showed that spending a lot of time playing video games/MMORPGs associated with low self-esteem (Colwell \& Payne, 2000; Fling et al., 1992; Funk \& Buchman, 1996) and low wellbeing (Allahverdipour et al., 2010; Durkin \& Barber, 2002; Kirby et al., 2014; Przybylski et al., 2012; Wack \& TantleffDunn, 2009).

On the other hand, consistently with the "harmonious passion" experience, some studies found that the sense of presence positively associated to self-needs satisfaction (Ryan et al., 2006), and they considered avatar identification as a way to integrate the avatar into the self and to reduce identity distress (Higgins, 1987; Klimmt et al., 2009; Mancini \& Sibilla, 2017).

Thus, the literature supported the validity of the model by Vallerand et al. (2003) in the context of video games and MMORPGs. Nevertheless, to best of our knowledge, no studies analyzed the paths between obsessive/harmonious game involvements and players' self-esteem and/or well-being over time. In general, several studies investigated the impact of videogames on well-being until now (Caplan et al., 2009; Kaczmarek \& Drążkowski, 2014; Kirby et al., 2014). Nevertheless, to the best of our knowledge, only one study on videogames (Jones et al., 2014) adopted the multidimensional well-being model by Seligman (2002). According to Seligman, well-being derives from three types of experience: pleasant, engaged, and meaningful life. Pleasant life refers to the hedonic well-being and is obtained through the experimentation of pleasant sensations and positive emotions. Engaged life indicates the well-being obtained via the gratification associated with commitment, carrying out satisfactory activities, and applying one's skills. Finally, meaningful life goes beyond just fulfilling the self's pleasures and desires: it refers to the well-being obtained through virtue, makes the person feel part of a global meaning and goal that transcends one's individuality, and therefore makes the person feel connected to a wider context.

\section{The Present Study}

Based on the aforementioned literature, the present longitudinal study had three goals. Goal A) was to explore whether IGD symptoms, presence, avatar identification, playing time could contribute to defining the two different types of involvement, i.e., Obsessive and Harmonious, for MMORPG players. The goal B) was to analyze the associations between the types of involvement and players' self-esteem and well-being. The goal C) was to analyze the direction of the associations between the types of involvement, self-esteem, and well-being.

Regarding goal A, in light of the literature results, we hypothesized that: 
H1: Regardless of the time-point of measurement, IGD symptoms, playing time, presence, and identification with the avatar would differentiate two types of involvement: an obsessive involvement, characterized by a close association between IGD symptoms and playing time; a harmonious involvement, characterized by a close association between presence, avatar identification, and IGD symptoms.

The literature suggested that the satisfaction of the self-needs, and in particular of self-esteem, has a crucial role in determining the type of game experience (Colwell \& Payne, 2000), with a low level of self-esteem associated with the riskier type of involvement. For this reason, as regards goal B, we hypothesized that:

H2: Regardless of the time-point of measurement, self-esteem would associate negatively with obsessive involvement and positively with harmonious involvement.

Given the lack of literature data suggesting the relationships between types of involvement with MMORPGs and Seligman's well-being dimensions, we formulated the following research question:

RQ1: How do obsessive and harmonious involvements associate with pleasant life, engaged life, and meaningful life?

Furthermore, because self-esteem is known to be positively associated with well-being (Ryan \& Deci, 2000), we hypothesized that:

H3: Regardless of the time-point of measurement, self-esteem would positively associate with pleasant life, engaged life, and meaningful life.

As to goal C, no studies are available that suggest the directionality of the cross-lagged effects between types of involvement, self-esteem, and well-being. Thus, the research question was:

RQ2: Which effects occur between obsessive and harmonious involvements, self-esteem, and pleasant, engaged, and meaningful life?

\section{Method}

\section{Study Design and Procedure}

The present study is based on the data from the three administrations of a longitudinal online survey ${ }^{1}$. The second wave (t2) was conducted one month after the first survey ( $\mathrm{t} 1$ ), while the third wave (t3) was conducted one month after the t2. Data were collected in the period from May to August 2018.

The survey was administered in Qualtrics (www.qualtrics.com) to a sample of MMORPG players recruited via calls for participation posted on Facebook groups dedicated to MMORPGs². To be eligible to participate in the study, participants had to be of age, MMORPG players, and to be willing to participate in the longitudinal study. For the various waves, the participation reminders were scheduled, managed, and sent using Qualtrics, which automatically matched the longitudinal responses from each participant. Data were collected and used complying with the Italian ethical standards and with the Declaration of Helsinki (World Medical Association, 2013).

\section{Participants}

In total, 360 participants accepted to participate in the longitudinal study ${ }^{3}$. Nevertheless, only 157 (43.6\%) completed $\mathrm{t} 1, \mathrm{t} 2$ and $\mathrm{t} 3$, and were therefore considered for this study. We excluded 10 of these 157 participants because, in one or more waves, they had not completed the self-esteem and/or well-being measures. Missing values on one-item measures related to the player's MMORPG involvement (i.e., Presence at t1 $=3$ missing, IOS at $\mathrm{t} 1=5$ missing, $\mathrm{IOS}$ at $\mathrm{t} 2=9$ missing, Presence at $\mathrm{t} 3=1$ missing, and $\mathrm{IOS}$ at $\mathrm{t} 3=4$ missing; see Measures) were replaced using multiple imputation with the Regression Method (see, e.g., Graham, 2009). 
One hundred and forty-seven participants ( 68 males, $46.3 \%$ and 79 females, 53.7\%, aged between 18 and 67 years; $M=31.98, S D=10.48$ ) made up the final sample. The majority of the participants responded from United States (53, 36.3\%), Italy (35, 23.8\%), and United Kingdom (9, 6.1\%). Twenty-five (17.0\%) of them came from other European countries, 11 (7.5\%) came from Canada, Australia, or New Zealand, 7 (4.8\%) from Asian countries, 4 from SouthAmerica, and 2 from South-Africa (1 missing).

More than half of the participants were workers (68, 46.6\% full-times workers and $11,7.5 \%$ part-time workers), fewer than $30 \%$ were students (33, 22.6\% full-time students and 7, 4.8\% students-workers), and 27 (18.5\%) were unemployed, homemakers or job-seekers.

All the participants declared that they were currently playing one or more MMORPGs. Only 25 (17.0\%) participants played the indicated MMORPG for less than 1 year, 62 (42.2\%) from a period between 1 and 3 years, 52 (35.4\%) from a period between 3 and 5 years, 9 (6.1\%) from a period between 6 and 10 years, and $9(6.1 \%)$ from more than 10 years. At $\mathrm{t} 1$, the mean number of hours spent in the previous 7 days playing with the MMORPG they indicated was $20.92(S D=17.93$, range $0-89)$.

\section{Measures}

At $\mathrm{t} 1, \mathrm{t} 2$, and $\mathrm{t} 3$ the participants completed the same questionnaire online. Given the international recruitment, two language versions of the questionnaire were available: an Italian version and an English version. Two distinct parts made up the questionnaire. The first part contained questions aimed to explore the type of involvement participants had with MMORPGs. The second part contained questions related to the participants' self-esteem and well-being.

\section{Type of Involvement With MMORPG Measures}

Two questions detected the MMORPG the participants had played the most in the previous month and how long they had been playing this MMORPG. The questions that followed concerned the game they indicated and were aimed to measure:

(a) Time, measured through a single item asking the number of hours and minutes spent playing the MMORPG in the previous seven days (excluding the survey administration day). As suggested by Yee (2006), the item was open-ended. Moreover, to favor the accuracy of the answer, the item was preceded by two other items identical to this one but referring to different time periods (Loftus et al., 1990).

(b) Presence, measured with the single item proposed by Slater and Usoh (1993): "When playing [...], to what extent do you experience a sense of being 'really there' inside the virtual environment?" Answers ranged from 1 (not at all) to 6 (totally).

(c) Avatar identification, measured with the one-item ideographic scale named Inclusion of Other in Self (IOS) proposed by Aron et al. (1992) and used in videogame studies to measure avatar identification (Gabbiadini et al., 2014; Mancini et al., 2019). The IOS version used in this study is composed of two circles representing "me" (i.e., the player's Self) and "my main avatar" (i.e., the main avatar the player had played with in the last month); the answer options corresponded to different degrees of overlap between the two circles. The sentence that introduced IOS was: "Now imagine that the circles on the left represent yourself and those on the right represent your main avatar. Please indicate which case best describes the level of overlap between you and your main avatar". Answers ranged from 1 (very far) to 8 (total overlap), with higher scores indicating a higher identification with the avatar.

(d) Internet Game Disorder symptoms, measured with the scale proposed by Hussain and Griffiths (2009). The scale was composed of 6 items ( $\alpha=.76, .80$, and .83 at $t 1, t 2$, and $t 3$ respectively, see Table 1 ) and each statement (e.g., "Online gaming is the most important thing in my life", "Conflicts have arisen between me and my family and/or my partner about the amount of online gaming I do") was measured on a five-point Likert type scale from 1 (strongly disagree) to 5 (strongly agree). A Confirmatory Factor Analysis (CFA) performed on data collected at t1 using M-PLUS v. 7.3 statistical package (L. K. Muthén \& B. O. Muthén, 1998-2012), and Maximum likelihood estimation with standard errors and a mean-adjusted robust chisquare test (MLR; Satorra \& Bentler, 2001), showed a good fit ${ }^{4}: \chi^{2}(9)=10.18, p=.33, \mathrm{CFI}=.998, \mathrm{TLI}=.996$, 
RMSEA $=.03,90 \% \mathrm{Cl}[.00, .10], p=.60, \mathrm{SRMR}=.045$, Sample-Size Adjusted BIC $=2047.55$. The six items were averaged to create the IGD score, in which a higher score indicated higher levels of gaming disorder.

\section{Self-Esteem}

It was measured with three items randomly selected from the Rosenberg Self-Esteem scale (Rosenberg, 1979). Items were rated on a 5-point Likert-type scale ranging from 1 (completely false) to 5 (completely true). The reliability of the scale was satisfactory $(a=.79, .72$, and .77 at $\mathrm{t} 1, \mathrm{t} 2$, and $\mathrm{t} 3$ respectively, see Table 1$)$.

\section{Well-Being}

It was measured with a short version of the Orientations to Happiness scale (Peterson et al., 2005). Nine items rated on a 5-point Likert-type scale ranging from 1 (very much unlike me) to 5 (very much like me) composed the scale. Three items asked the participants to express their agreement with three statements referred to life of meaning (e.g., "My life has a lasting meaning"), three items referred to life of pleasure (e.g., "In choosing what to do, I always take into account whether it will be pleasurable"), and three items referred to life of engagement (e.g., "I am always very absorbed in what I do"). We checked for the dimensionality of the scale comparing the one-dimensional solution with a three-dimensional solution (CFA, MLR; Satorra \& Bentler, 2001), at t1. The one-dimensional structure had not an acceptable fit: $\chi^{2}(27)=103.97, p<.001, \mathrm{CFI}=.596, \mathrm{TLI}=.462$, RMSEA $=.139, p>.001,90 \% \mathrm{Cl}$ $[.11, .17]$, SRMR $=.113$, Sample-Size Adjusted BIC $=4142.27$. Conversely, when a three-dimensional structure was considered, an acceptable fit was obtained: $\chi^{2}(24)=24.20, p=.45, \mathrm{CFI}=.999, \mathrm{TLI}=.998$, RMSEA $=.008, p=.83,90 \%$ $\mathrm{Cl}[.00, .07], \mathrm{SRMR}=.053$, Sample-Size Adjusted BIC $=4063.992$. Thus, items were averaged to create three scores: Meaningful, Engaged, and Pleasant life, in which higher scores indicated higher levels of happiness in the respective dimension.

Inter-waves correlations and Cronbach's alpha coefficients at t1, t2, and t3 are presented in Table 1.

\section{Results}

\section{Preliminary Analyses}

Descriptive statistics are presented in Table 1.

The amount of time spent playing the MMORPG decreased slightly from $\mathrm{t} 1$ ( $M=20.92 \mathrm{~min})$ to $\mathrm{t} 2$ ( $M=16.75 \mathrm{~min}$; $t(146)=3.03, p<.01)$, while it increased slightly from t2 to $t 3(M=20.16 \mathrm{~min} ; t(146)=-2.28, p<.05)$, returning to the t1 level. A similar trend was observed for Presence, IOS, and IGD. In fact, Presence $\left(M_{\mathrm{t} 1}=3.29\right.$ and $M_{\mathrm{t} 2}=2.94$; $t(146)=3.93, p<.001), I O S\left(M_{\mathrm{t} 1}=4.47\right.$ and $\left.M_{\mathrm{t} 2}=4.21 ; t(146)=2.19, p<.05\right)$, and $I G D\left(M_{\mathrm{t} 1}=2.71\right.$ and $M_{\mathrm{t} 2}=2.53 ; t(146)$ $=4.01, p<.001$ ) slightly decreased from $\mathrm{t} 1 \mathrm{to} \mathrm{t} 2$, but not significantly changed from t2 and t3. Instead, Self-esteem, Meaningful life, Engaged life, and Pleasant life did not change significantly from $\mathrm{t} 1 \mathrm{to} \mathrm{t} 2$, and they also remained stable from $\mathrm{t} 2$ to $\mathrm{t} 3$.

In order to control for gender and age effects, we subsequently performed zero-order correlations. Gender (female $=1$ ) did not correlate with gaming involvement variables ( $r$ 's ranging from .02 to .19, $p>.01$ ), with selfesteem ( $r$ 's ranging from -.06 to $-.13, p>.01$ ), and with well-being ( $r$ 's ranging from .04 to $.18, p>.01$ ) at all the three time points. Age was correlated negatively but not significantly $(p>.01)$ with the gaming involvement variables ( $r^{\prime}$ s ranging from -.03 to -.20$)$, but it was correlated positively and significantly with self-esteem $\left(r_{\mathrm{t} 1}=.36\right.$, $\left.r_{\mathrm{t} 2}=.40, r_{\mathrm{t} 3}=.38, p<.001\right)$ and with meaningful life $\left(r_{\mathrm{t} 1}=.26, r_{\mathrm{t} 2}=.22, r_{\mathrm{t} 3}=.22, p=.01\right)$ at all the three time points. 
Table 1. Descriptive Statistics, Cronbach's Alpha Coefficients, and Inter-Waves Correlations of the Variables Measured at $t 1, t 2$, and $t 3$.

\begin{tabular}{|c|c|c|c|c|c|c|c|c|c|c|c|c|c|c|c|c|c|c|c|c|c|c|c|c|c|c|c|}
\hline & & $M$ & $S D$ & 1 & 2 & 3 & 4 & 5 & 6 & 7 & 8 & 9 & 10 & 11 & 12 & 13 & 14 & 15 & 16 & 17 & 18 & 19 & 20 & 21 & 22 & 23 & 24 \\
\hline 1 & t1_Time & 20.92 & 17.93 & - & & & & & & & & & & & & & & & & & & & & & & & \\
\hline 2 & t1_Presence & 3.29 & 1.28 & $.20^{*}$ & - & & & & & & & & & & & & & & & & & & & & & & \\
\hline 3 & t1_Identification & 4.47 & 1.70 & -.08 & $.29^{* *}$ & - & & & & & & & & & & & & & & & & & & & & & \\
\hline 4 & t1_IGD & 2.71 & 0.76 & $.43^{* *}$ & $.48^{* *}$ & $.24^{* *}$ & .76 & & & & & & & & & & & & & & & & & & & & \\
\hline 5 & t1_Self-esteem & 3.26 & 1.05 & -.08 & -.11 & .06 & -.15 & .79 & & & & & & & & & & & & & & & & & & & \\
\hline 6 & t1_Meaning. life & 3.07 & 1.08 & $-.17 *$ & .01 & .11 & -.10 & $.51^{* *}$ & .59 & & & & & & & & & & & & & & & & & & \\
\hline 7 & t1_Engaged life & 3.08 & 0.89 & .10 & $.27^{* \star}$ & .08 & $.47^{* *}$ & -.14 & -.09 & .79 & & & & & & & & & & & & & & & & & \\
\hline 8 & t1_Pleasant life & 3.43 & 0.84 & .03 & .14 & .12 & .08 & .12 & $.22^{* *}$ & .12 & .55 & & & & & & & & & & & & & & & & \\
\hline 9 & t2_Time & 16.75 & 15.90 & $.52^{* *}$ & .15 & -.07 & $.29^{* *}$ & $-.17^{*}$ & $-.28^{* *}$ & .05 & -.04 & - & & & & & & & & & & & & & & & \\
\hline 10 & t2_Presence & 2.94 & 1.39 & .14 & $.68^{* *}$ & $.19^{*}$ & $.37^{* \star}$ & -.09 & .03 & $.27^{* \star}$ & .02 & .15 & - & & & & & & & & & & & & & & \\
\hline 11 & t2_Identification & 4.21 & 1.55 & -.07 & $.27^{* *}$ & $.62^{* *}$ & $.17^{\star}$ & .01 & .12 & .04 & $.17^{*}$ & -.09 & $.24^{\star *}$ & - & & & & & & & & & & & & & \\
\hline 12 & t2_IGD & 2.53 & 0.75 & $.28^{* *}$ & $.50^{* *}$ & $.27^{* *}$ & $.73^{* *}$ & $-.25^{* *}$ & $-.20^{*}$ & $.46^{* *}$ & .10 & $.37^{* \star}$ & $.46^{* *}$ & $.22^{* *}$ & .80 & & & & & & & & & & & & \\
\hline 13 & t2_Self-esteem & 3.27 & 0.96 & -.10 & -.08 & .01 & $-.17^{*}$ & $.84^{* *}$ & $.50^{* *}$ & -.11 & .10 & -.13 & -.05 & -.01 & $-.26^{* *}$ & .72 & & & & & & & & & & & \\
\hline 14 & t2_Meaning. life & 3.11 & 1.12 & -.14 & -.04 & .05 & -.11 & $.44^{* *}$ & $.82^{* *}$ & -.09 & .12 & $-.22^{* *}$ & .05 & .10 & $-.19^{*}$ & $.46^{* *}$ & .68 & & & & & & & & & & \\
\hline 15 & t2_Engaged life & 3.12 & 0.85 & .13 & $.26^{* *}$ & .11 & $.43^{* *}$ & -.01 & .07 & $.68^{* *}$ & $.20^{*}$ & .09 & $.27^{* *}$ & .05 & $.43^{* *}$ & .01 & .09 & .88 & & & & & & & & & \\
\hline 16 & t2_Pleasant life & 3.49 & 0.82 & .01 & $.17^{*}$ & .11 & .14 & $.16^{*}$ & $.22^{* *}$ & .11 & $.74^{\star *}$ & -.06 & .05 & $.21^{*}$ & $.18^{*}$ & .12 & $.18^{*}$ & $.17^{*}$ & .69 & & & & & & & & \\
\hline 17 & t3_Time & 20.16 & 19.28 & $.43^{* *}$ & .09 & -.06 & $.31^{* *}$ & $-.20^{*}$ & $-.26^{* *}$ & .12 & -.05 & $.48^{* *}$ & .05 & .03 & $.31^{* *}$ & $-.21^{*}$ & $-.26^{* *}$ & .08 & -.03 & - & & & & & & & \\
\hline 18 & t3_Presence & 3.00 & 1.32 & .08 & $.71^{* \star}$ & $.27^{* *}$ & $.45^{* *}$ & -.07 & .02 & $.29^{* *}$ & .10 & .05 & $.76^{* *}$ & $.36^{* *}$ & $.50^{* \star}$ & -.05 & .01 & $.29^{* *}$ & .15 & .14 & - & & & & & & \\
\hline 19 & t3_Identification & 4.18 & 1.49 & -.09 & $.30^{* *}$ & $.62^{* *}$ & $.20^{*}$ & .03 & .12 & .09 & .08 & -.09 & $.32^{* *}$ & $.77^{* \star}$ & $.28^{* *}$ & .04 & .06 & .16 & .16 & -.04 & $.42^{* *}$ & - & & & & & \\
\hline 20 & t3_IGD & 2.56 & 0.80 & $.25^{* *}$ & $.40^{* *}$ & $.20^{*}$ & $.74^{* *}$ & $-.30^{* *}$ & -.16 & $.43^{* *}$ & .03 & $.26^{* \star}$ & $.42^{* *}$ & $.25^{* *}$ & $.83^{* *}$ & $-.31^{* *}$ & -.16 & $.45^{* *}$ & .11 & $.44^{\star *}$ & $.53^{* *}$ & $.27^{* *}$ & .83 & & & & \\
\hline 21 & t3_Self-esteem & 3.30 & 0.97 & -.10 & -.10 & .01 & $-.16^{*}$ & $.83^{* *}$ & $.51^{* *}$ & $-.17^{*}$ & .12 & -.14 & -.08 & -.01 & $-.25^{* *}$ & $.85^{* \star}$ & $.46^{* *}$ & -.03 & .15 & -.16 & -.03 & .02 & $-.29^{* *}$ & .77 & & & \\
\hline 22 & t3_Meaning. life & 3.15 & 1.15 & -.14 & -.03 & .04 & -.12 & $.46^{* *}$ & $.85^{* *}$ & -.09 & .14 & $-.25^{* *}$ & .05 & .07 & $-.22^{* \star}$ & $.48^{* *}$ & $.90^{* *}$ & .02 & .16 & $-.24^{* *}$ & .01 & .06 & $-.18^{*}$ & $.51^{* *}$ & .66 & & \\
\hline 23 & t3_Engaged life & 3.16 & 0.84 & .15 & $.22^{* *}$ & .07 & $.39^{* *}$ & -.03 & .07 & $.60^{\star *}$ & $.21^{*}$ & .12 & $.30^{* *}$ & .09 & $.40^{* *}$ & -.03 & .09 & $.78^{* *}$ & $.21^{*}$ & .11 & $.29^{* *}$ & .16 & $.42^{* *}$ & .01 & .05 & .89 & \\
\hline 24 & t3_Pleasant life & 3.52 & 0.82 & .11 & $.20^{*}$ & .13 & $.22^{* *}$ & .05 & .10 & $.21^{*}$ & $.68^{* *}$ & .05 & .13 & $.17^{*}$ & $.24^{* *}$ & .06 & .05 & $.34^{* *}$ & $.77^{\star *}$ & .01 & $.23^{* *}$ & .14 & $.18^{*}$ & .11 & .05 & $.33^{* *}$ & .67 \\
\hline
\end{tabular}

Note. ${ }^{* *} p<.01,{ }^{*} p<.05$ ( $\left.N=147\right)$ : Cronbach's alpha coefficients in the diagonal. 


\section{PAFs on Measures of MMORPG Players' Involvement (Goal A)}

To identify the different types of involvement with MMORPGs (goal A) we conducted three Principal Axis Factoring (PAF) analyses - with Varimax rotation and Kaiser normalization method - on time, presence, avatar identification, and IGD measured at $\mathrm{t} 1$, $\mathrm{t} 2$, and $\mathrm{t} 3$. On $\mathrm{t} 1$, $\mathrm{t} 2$, and $\mathrm{t} 3$, PAFs extracted two factors with eigenvalues $>1$ that explained the $47.22 \%, 43.57 \%$, and $52.15 \%$ of variance, respectively. Table 2 reports the factor scores of the three analyses. Regardless of measurement times, the analyses highlighted two different types of involvement with MMORPGs that we named obsessive involvement and harmonious involvement. In accordance with H1, IGD scores saturated both factors, while they associated with different components of the gaming experience: in the Obsessive involvement factor, IGD saturated with the playing time, while in the Harmonious involvement factor, IGD saturated with the presence and with the avatar identification (IOS). In order to keep the orthogonality of the factors, factor scores were saved using the Anderson-Rubin method ( $M=0 ; S D=1, r=0)$.

Table 2. Rotated (Varimax With Kaiser Normalization) Factor Matrics at t1, t2, and t3.

\begin{tabular}{|c|c|c|c|c|c|c|}
\hline & \multicolumn{2}{|c|}{$t 1$} & \multicolumn{2}{|c|}{$t 2$} & \multicolumn{2}{|c|}{ t3 } \\
\hline & $\begin{array}{l}\text { Harmonious } \\
\text { involvement }\end{array}$ & $\begin{array}{c}\text { Obsessive } \\
\text { involvement }\end{array}$ & $\begin{array}{l}\text { Harmonious } \\
\text { involvement }\end{array}$ & $\begin{array}{c}\text { Obsessive } \\
\text { involvement }\end{array}$ & $\begin{array}{l}\text { Harmonious } \\
\text { involvement }\end{array}$ & $\begin{array}{c}\text { Obsessive } \\
\text { involvement }\end{array}$ \\
\hline Time & -.06 & .69 & -.03 & .66 & -.03 & .66 \\
\hline Presence & .54 & .34 & .53 & .26 & .72 & .25 \\
\hline IOS & .58 & -.07 & .52 & -.12 & .59 & -.03 \\
\hline IGD & .48 & .66 & .57 & .59 & .50 & .69 \\
\hline
\end{tabular}

\section{Longitudinal Cross-Lagged Analyses (Goals B and C)}

We used structural equation models to test intra-wave associations and cross-lagged effects between the types of involvement, self-esteem, and well-being dimensions (goals B and C). The analyses were performed in Mplus 7.3 (L. K. Muthén \& B. O. Muthén, 1998-2012), using the maximum likelihood estimator (Satorra \& Bentler, 2001). Due to the sample size $(N=147)$, we conducted three separate analyses, one for each Well-being dimension: Meaningful life (Model 1), Engaged life (Model 2) and Pleasant life (Model 3). In each model we tested: a) crosslagged paths: from the two types of involvement (i.e., obsessive involvement and harmonious involvement) to selfesteem and well-being dimensions, and from self-esteem and well-being to the two types of involvement (i.e., obsessive involvement and harmonious involvement); from obsessive involvement to harmonious involvement, and vice versa; from self-esteem to well-being dimensions, and vice versa; b) stability paths controlling for measurement time (e.g., obsessive involvement at t1 predicting obsessive involvement at t2, obsessive involvement at $\mathrm{t} 2$ predicting obsessive involvement at $\mathrm{t} 3$ ); and c) within-time correlations among all the variables, with the exception of correlations between obsessive and harmonious involvement that we fixed to 0 in all models. We assessed the model fit according to the recommendations of Byrne (2012) and Kenny (2015; see Footnote 4).

To model the longitudinal associations as parsimoniously as possible, we first of all tested whether the crosslagged effects and the $\mathrm{t} 1-\mathrm{t} 3$ within-wave correlations were time invariant, comparing the baseline unconstrained models (M1.1, M2.1, M3.1) with: a) the models assuming time invariance of the cross-lagged associations and of the $\mathrm{t} 1$ - $\mathrm{t} 3$ within-time correlations (M1.2, M2.2, M3.2), and b) the models assuming time invariance of the t1-t3 within-time correlations (M1.3, M2.3, M3.3). Significant differences between the models were determined according to three criteria: $\Delta \chi_{S B}{ }^{2}$ significant at $p<.05$ (Satorra \& Bentler, 2001), $\Delta C F I \geq .010$, and $\triangle \mathrm{RMSEA} \geq .015$ (Chen, 2007). At least two of these three criteria had to be met.

Findings (see Table 3) did not support the assumption of time invariance for Model 1 and Model 2, but supported the assumption of within-time correlations invariance for Model 3. Thus, only in this case did we retain the most parsimonious model (M3.3). Results of the three models are synthetized in Figures 1, 2, and 3. The complete results are included in the Supplementary material (Tables S1-S3). 
Table 3. Cross-Lagged Models: Fit Indices and Model Comparisons.

\begin{tabular}{|c|c|c|c|c|c|c|c|c|c|c|c|c|}
\hline & \multicolumn{6}{|c|}{ Model fit indices } & \multicolumn{6}{|c|}{ Model comparison } \\
\hline & $X \mathrm{SB}^{2}$ & $d f$ & $\mathrm{CFI}$ & TLI & RMSEA $[90 \% \mathrm{Cl}]$ & SRMR & MODELS & $\Delta \mathrm{XSB}^{2}$ & $\Delta d f$ & $p$ & $\Delta \mathrm{CFI}$ & $\triangle \mathrm{RMSEA}$ \\
\hline \multicolumn{13}{|l|}{ M1 - Meaningful life } \\
\hline M1.1 Baseline (unconstrained) & 26.383 & 15 & .989 & .958 & $.072[.020, .116]$ & .024 & & & & & & \\
\hline $\begin{array}{l}\text { M1.2 Cross-lagged paths and } \mathrm{t} 1-\mathrm{t} 3 \text { within- } \\
\text { time correlations fixed to be time invariant }\end{array}$ & 108.603 & 43 & .939 & .915 & $.102[.078, .126]$ & .152 & $\mathrm{M} 1.2-\mathrm{M} 1$ & 80.591 & 28 & $<.001$ & -.050 & .030 \\
\hline $\begin{array}{l}\text { M1.3 t1-t3 within-time correlations fixed to } \\
\text { be time invariant }\end{array}$ & 74.095 & 25 & .954 & .891 & $.116[.086, .146]$ & .134 & $\mathrm{M} 1.3-\mathrm{M} 1$ & 46.562 & 10 & $<.001$ & -.035 & .044 \\
\hline \multicolumn{13}{|l|}{ M2 - Engaged life } \\
\hline M2.1 Baseline (unconstrained) & 32.032 & 15 & .981 & .925 & $.088[.045, .130]$ & .027 & & & & & & \\
\hline $\begin{array}{l}\text { M2.2 Cross-lagged paths and } \mathrm{t} 1 \text { - } \mathrm{t} 3 \text { within- } \\
\text { time correlations fixed to be time invariant }\end{array}$ & 99.468 & 43 & .938 & .913 & $.095[.070, .119]$ & .134 & $\mathrm{M} 2.2-\mathrm{M} 2$ & 67.190 & 28 & $<.001$ & -.043 & .007 \\
\hline $\begin{array}{l}\text { M2.3 } \mathrm{t} 1-\mathrm{t} 3 \text { within-time correlations fixed to } \\
\text { be time invariant }\end{array}$ & 61.504 & 25 & .960 & .903 & $.100[.068, .131]$ & .091 & $\mathrm{M} 2.3-\mathrm{M} 2$ & 29.328 & 10 & .001 & -.021 & .012 \\
\hline \multicolumn{13}{|l|}{ M3 - Pleasant life } \\
\hline M3.1 Baseline (unconstrained) & 28.894 & 15 & .984 & .938 & $.079[.033, .123]$ & .026 & & & & & & \\
\hline $\begin{array}{l}\text { M3.2 Cross-lagged paths and } \mathrm{t} 1-\mathrm{t} 3 \text { within- } \\
\text { time correlations fixed to be time invariant }\end{array}$ & 77.205 & 43 & .962 & .946 & $.074[.046, .100]$ & .095 & M3.2 - M3 & 48.543 & 28 & .009 & -.022 & -.005 \\
\hline $\begin{array}{l}\text { M3.3 t1-t3 within-time correlations fixed to } \\
\text { be time invariant }\end{array}$ & 40.006 & 25 & .983 & .960 & $.064[.021, .099]$ & .052 & M3.3 - M3 & 11.374 & 10 & .329 & -.001 & -.015 \\
\hline
\end{tabular}

Note. $\Delta \mathrm{XSB}^{2}$ model comparisons are based on Satorra and Bentler's (2001) scaled difference chi-square test statistic. $d f=$ Degrees of Freedom. TLI = TuckerLewis index; $\mathrm{CFI}=$ Comparative Fit Index;

RMSEA = Root Mean Square Error of Approximation; $90 \% \mathrm{Cl}=90 \%$ Confidence Interval; SRMR = Standardized Root Mean Square Residual; $\Delta=$ change in parameter.

\section{Meaningful Life (M1.1)}

The model had a good data fit (see Table 3). The stability of the model's variables was high from t1 to t2 and from t2 to t3 (standardized betas ranging from .81 and .39, all $p$ values $<.001$ ), while it was moderate from t 1 to t3 (standardized betas ranging from .21, $p<.01$, and .40, $p<.001$ ), as indicated in Figure 1. Cross-lagged effects indicated that obsessive involvement with video games at $\mathrm{t} 1$ positively influenced the harmonious involvement with video games at $\mathrm{t} 2$. Furthermore, players' self-esteem at $\mathrm{t} 2$ negatively influenced obsessive involvement at $\mathrm{t} 3$, while meaningful life at $\mathrm{t} 1$ negatively influenced obsessive involvement at $\mathrm{t} 2$. Specifically, self-esteem and meaningful life predicted changes in players' MMORPG experience, decreasing obsessive involvement with video games, partially supporting H2. Intra-waves correlations showed self-esteem and meaningful life significantly and positively associated both at $\mathrm{t} 1$ and at $\mathrm{t} 3$, thus partially supporting $\mathrm{H} 3$.

\section{Engaged Life (M2.1)}

The model had a good data fit (see Table 3). As for meaningful life, the stability of the model's variables was high from $\mathrm{t} 1$ and to $\mathrm{t} 2$ and from $\mathrm{t} 2$ to $\mathrm{t} 3$ (standardized betas ranging from .84 and .39, all $p$ values $<.001$ ), and was moderate from t1 to $\mathrm{t} 3$ (standardized betas ranging from .13, $p=.05$, and .39, $p<.001$ ), as indicated in Figure 2. Nevertheless, unlike M1.1, obsessive involvement did not influence harmonious involvement. Instead, as for M1.1, both at $\mathrm{t} 1$ and at $\mathrm{t} 2$, self-esteem predicted changes in players' MMORPG experience, decreasing obsessive involvement. However, obsessive involvement with video games at $\mathrm{t} 1$ slightly but significantly influenced wellbeing at $\mathrm{t} 2$, increasing engaged life. Both harmonious involvement and obsessive involvement with video games significantly and positively correlated with engaged life at t1. Moreover, as M1.1, self-esteem and engaged life were positively associated at $\mathrm{t} 3$, thus partially supporting $\mathrm{H} 3$. 
Figure 1. Significant $(p<.05)$ Standardized Betas of the Cross-Lagged Unconstrained Model for Meaningful Life (Model 1.1).



Note. Har = Harmonious involvement; Obs = Obsessive involvement; Est = Self-esteem; Mea = Meaningful life.

Figure 2. Significant $(p<.05)$ Standardized Betas of the Cross-Lagged Unconstrained Model for Engaged Life (Model 2.1).

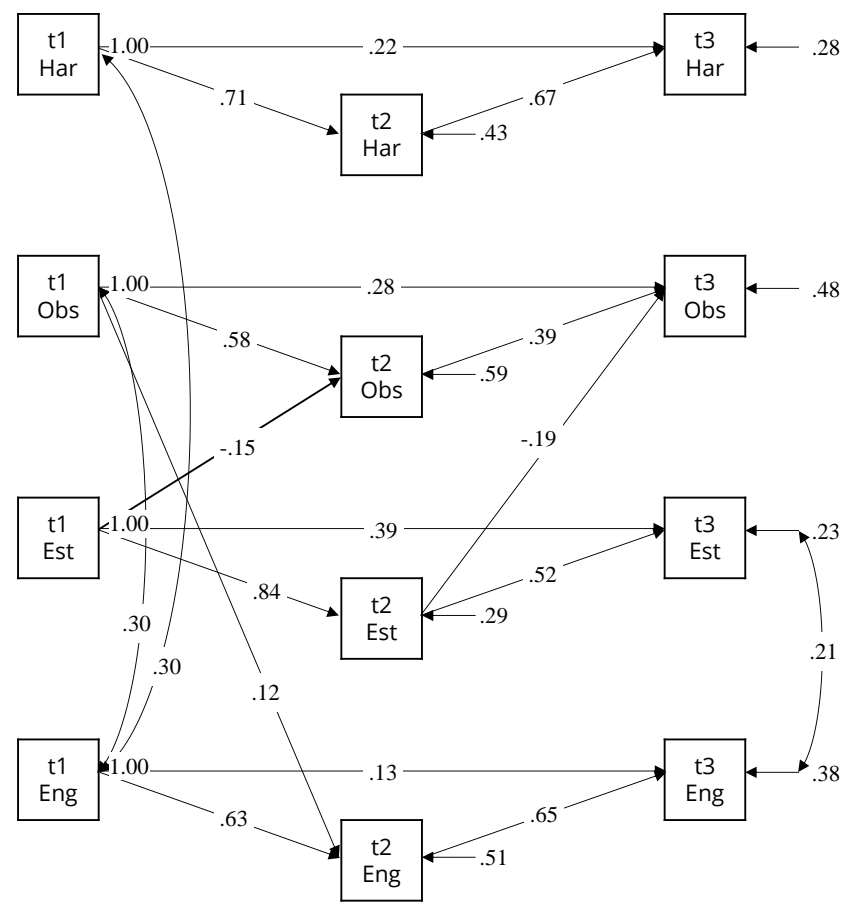

Note. Har = Harmonious involvement; Obs = Obsessive involvement; Est = Self-esteem; Eng = Engaged life.

\section{Pleasant Life (M3.3)}

The model with $\mathrm{t} 1$-t3 within-time correlations fixed to be time-invariant (M3.3, see Table 3) had a good data fit. As indicated in Figure 3, as for M1.1 and M2.1, the stability of the model's variables was high from t1 to t2 and from t2 to t3 (standardized betas ranging from .84 and .40, all $p$ values $<.001$ ), and was moderate from t 1 to t3 (standardized betas ranging from .21, $<<.01$ and .40, $p<.001$ ). As for the previous models, cross-lagged effects highlighted that both at $\mathrm{t} 1$ and at $\mathrm{t} 2$, players' self-esteem negatively influenced obsessive involvement with video games. Instead, no variables predicted pleasant life, which was significantly and positively correlated with harmonious involvement to video games regardless of the measurement time. Instead, intra-waves correlations 
between self-esteem and pleasant life (fixed to be time-invariant) were not statistically significant, thus not supporting $\mathrm{H} 3$.

Figure 3. Significant $(p<.05)$ Standardized Betas of the Cross-Lagged Within-Time Correlations Invariant Model for Pleasant Life (Model 3.3).

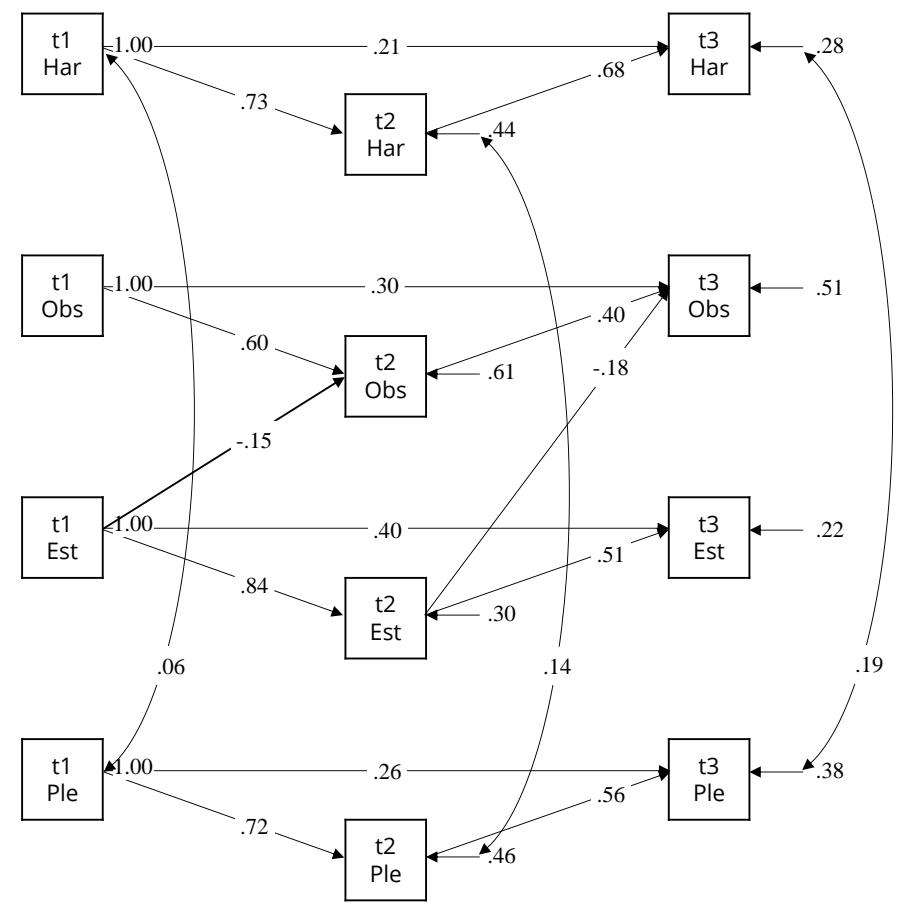

Note. Har = Harmonious involvement; Obs = Obsessive involvement; Est $=$ Self-esteem; Ple = Pleasant life.

\section{Discussion}

The present study wanted to contribute to the debate concerning problematic and non-problematic involvement in video games (e.g., Billieux et al., 2019). It aimed to explore how relevant game variables (i.e., IGD symptoms, presence, avatar identification, playing time) combine in defining the two different types of involvement described in the literature (Fuster et al., 2014; Przybylski et al., 2009; Vallerand et al., 2003), i.e., obsessive and harmonious, in MMORPG players. Moreover, it also aimed to evaluate the relationships between types of game involvement, self-esteem, and well-being by using a longitudinal design.

Results supported the hypothesis $1(\mathrm{H} 1)$, revealing two types of game involvement both characterized by IGD symptoms, yet different in the other game experience variables. The present findings are in line with and expand the previous empirical studies on this issue (Fuster et al., 2014; Przybylski et al., 2009), showing that IGD symptoms play a role in both involvement types, but they differently relate with players' well-being depending on the ways subjects are involved in the game experience. Thus, our findings further support the need to distinguish between high - i.e., a passion - and pathological - i.e., obsessive - involvement in video games, in order to avoid the pathologization of behaviors that do not really define a clinically significant condition (e.g., Musetti et al., 2019).

The present study showed that self-esteem protects from obsessive involvement over time (RQ2). One could speculate that players with low self-esteem attempt to regulate the need for self-esteem by playing and performing well in the game (Crocker \& Wolfe, 2001; Vallerand et al., 2003). This supports the idea that the obsessive involvement is an external and behavioral participation in the game that is aimed at finding in the game activity some feedbacks that could increase the level of self-esteem. Feedbacks that could be useful for this purpose may be getting achievements in the game. On the other hand, a high self-esteem keeps the user from becoming obsessively involved in the game, since in this case there is no need to use the game as a means to regulate the perceived personal value; the absence of this need can lead the person to focus not on the behavioral performance but on the processual gaming experience. Furthermore, results showed that obsessive involvement is not cross-sectionally correlated to player's self-esteem $(\mathrm{H} 2)$ nor it affects self-esteem over time, suggesting that obsessive involvement is an ineffective strategy for regulating this self-need (e.g., Crocker \& Wolfe, 2001). 
The present study also examined the association between the two types of involvement and the user's well-being, measured in terms of meaningful life, engaged life, and pleasant life (Peterson et al., 2005) (RQ1). The literature had already pointed out that involvement with video games can be pleasant (Billieux et al., 2019) and that pleasure is one of the factors that explains a progressive increase in gaming that has nothing to do with pathology (Kardefelt-Winther, 2015). Our data partially supported this trend, showing that, regardless of the measurement time, harmonious involvement associated with the hedonic pleasure, providing for a player's significant participation in the gaming experience. Moreover, data also showed that obsessive involvement can sometimes associate with engaged life (RQ2). As the Authentic Happiness Theory by Seligman (2002) underlines, engaged life can be reached through absorbing activities carried out with a subjective experience of emotional void (Schueller \& Seligman, 2010). Thus, playing in a position of complete "loss of self" (Scorsolini-Comin et al., 2013), in which a video game player has a scarce awareness of his or her true sensations, could be a gratifying experience, probably allowing gamers relaxation and emotional relief through a self-absorption escape mechanism (Deleuze et al., 2019; Schimmenti \& Caretti, 2010). However, it is likely that for the video game players with a pre-existing psychopathology, this kind of game use could turn into an unhealthy defense mechanism to dissociate unbearable mental states from consciousness (Musetti et al., 2019; Schimmenti et al., 2012). Results also showed that a high level of meaningful life can sometimes discourage the player to engage in the video game in an obsessive way. This finding suggests that an individual who recognizes, cultivates, and applies his or her own virtues is less prone to engaging in video games in a behavioral and performative sense. In fact, while hedonic well-being (which associates with the pleasant life dimension) is based on the escape from negative emotional states and the search for immediate pleasure, eudaimonic well-being (which associates with the meaningful life dimension) is characterized by a greater awareness and tolerability of internal states (Riva et al., 2012; Ryan \& Deci, 2001; Ryff, 2014). In this sense, high levels of meaningful life can reduce the likelihood that, in response to unsatisfied needs, the person engages in an obsessive game.

Although these results were not always strong and stable, they did highlight two important aspects. First, the positive correlation between harmonious involvement and hedonic or engaged well-being strengthens the idea that the IGD symptoms present in this kind of involvement may not reflect a really clinically significant condition, but rather they are only apparent symptoms. Second, the negative association between meaningful life and obsessive involvement suggests the compensatory role obsessive involvement can have for MMORPG players. In other words, if emotionally immersing yourself in the game is associated with well-being, especially the hedonic and engaged types of well-being, the lack of well-being, and especially a low perceived meaning in life, can foster compulsive game modes, i.e., obsessive involvement. This obsessive way of playing is encouraged by low selfesteem (RQ2). Hence, it is not surprising that well-being - with the exception of the pleasant life dimension - also positively associated with self-esteem, as we hypothesized $(\mathrm{H} 3)$ and in line with the theoretical model of Peterson et al. (2005). These results are consistent with the compensatory gaming framework (Allen \& Anderson, 2018; Di Blasi et al., 2020; Kardefelt-Winther, 2014a; Mills et al., 2018; Przybylski \& Weinstein, 2019).

\section{Limitations and Strengths}

This study has some limitations. First, the sample size was relatively small (albeit statistically sufficient) and included only adult volunteers from the normal population, so the present findings are not generalizable to the population at large. Studies with a larger sample size, with clinical and nonclinical samples, are needed to extend our results and to further our knowledge in this area. It should be considered that an unexpectedly large number of the participants in the present study were females, while some studies show that MMORPG players are predominantly male (Yee, 2006). However, it must be noted that the current number of female video gamers is substantial and it is increasing (Entertainment Software Association, 2020). Also, due to space constraints in the questionnaire, some single-item measures were used: this can be considered a further limitation of the study. Future studies could improve these measurements and verify their validity. Given that the present study adopted a dimensional approach, it was not possible to provide results that support the distinction between core and peripheral criteria of IGD (e.g., Brunborg et al., 2013; Charlton, 2002; Charlton \& Danforth, 2007, 2010; LehenbauerBaum et al., 2015; Lehenbauer-Baum \& Fohringer, 2015). More studies will be needed to explore how specific symptoms of IGD and game experience variables connect to each other in determining a pathological or a passionate involvement with video games; in this sense, future studies could identify which symptoms are more associated with maladaptive use, and which with benign use/high engagement. Moreover, a different way of 
approaching it would be to consider IGD symptoms as predictors of harmonious versus obsessive involvement, instead of including them as part of the involvement.

Moreover, other variables that could have a role within the investigated relationships have not been considered, such as psychopathologies or other predisposing factors beyond self-esteem, e.g., the attachment style or the personality of the player. Future longitudinal studies should assess the relationship between psychopathological symptoms and obsessive involvement in video game playing. Finally, the three waves ( $t 1, t 2$, and $t 3$ ) were conducted in three months, one month apart from each other. These intervals may have been too short for meaningful changes to occur. Longer longitudinal studies could test whether the longitudinal effects we observed in the short-term also occur in the medium/long-term.

However, the study also has some strengths. First, the investigation was conducted on an international sample. Moreover, the data were collected in a longitudinal design, which allowed us to obtain better results on the relationships between the investigated variables. Furthermore, well-being was measured in multidimensional terms, which allowed us to understand the relationships that self-esteem and the two types of involvement have with specific and different forms of well-being.

\section{Implications}

The current findings can have interesting practical implications, especially in clinical settings. In fact, the characterization of the two types of game involvement suggests that variables such as the time spent playing, the presence that is perceived when playing, and the identification with the avatar are relevant aspects to assess together with IGD symptoms in order to fully and thoroughly understand how the player relates to the game and what risks that kind of involvement has. This broader and more accurate assessment would allow to avoid the pathologization of people who have a high but harmonious involvement with the game, and it would allow to better identify the people who need treatment. At the same time, this kind of assessment would lay the foundations for a more complex and process-based treatment. In addition, the current findings show that selfesteem is an important factor on which we can intervene to prevent risky forms of game involvement. In this sense, widespread trainings aimed at satisfying basic psychological needs - and especially self-esteem - could be useful tools to prevent cases of problematic video game use. Furthermore, self-esteem trainings could also be carried out with current gamers in order to prevent or reduce problematic videogame use and consequently to protect or improve their personal well-being.

\section{Footnotes}

1. The longitudinal study originally included 4 waves; the second wave was excluded from this study because it was conducted 14 days after the first one.

2. Some Facebook groups in which the announcement was posted are:

"The Elder Scrolls Online" (https://www.facebook.com/groups/ElderScrolls.Online), "Guild Wars 2 and Expansions" (https://www.facebook.com/groups/GuildWars2andXPs), and "World of Warcraft Players" (https://www.facebook.com/groups/worldofwarcraftnerds)

3. This study is part of a wider cross-sectional study that involved 1538 participants, mostly (92\%) current or past video game or MMORPG players (Sibilla, 2019).

4. Multiple indices of Comparative fit index (CFI), Tucker Lewis index (TLI), Root mean square error of approximation (RMSEA) and Standardized root mean square residual (SMSR) were used to assess the fit of the models presented in this study. Usually, CFI and TLI values greater than .95 as well as SMSR value lower than .05 indicate an excellent model fit; values of CFI higher than .90 and of RMSEA smaller than .08 are indicative of an acceptable fit (Byrne, 2012; Kenny, 2015). 


\section{References}

Aarseth, E., Bean, A. M., Boonen, H., Colder Carras, M., Coulson, M., Das, D., Deleuze, J., Dunkels, E., Edman, J., Ferguson, C. J., Haagsma, M. C., Helmersson Bergmark, K., Hussain, Z., Jansz, J., Kardefelt-Winther, D., Kutner, L., Markey, P., Nielsen, R. K. L., Prause, N., ... Van Rooij, A. J. (2017). Scholars' open debate paper on the World Health Organization ICD-11 Gaming Disorder proposal. Journal of Behavioral Addictions, 6(3), 267-270. https://doi.org/10.1556/2006.5.2016.088

Allahverdipour, H., Bazargan, M., Farhadinasab, A., \& Moeini, B. (2010). Correlates of video games playing among adolescents in an Islamic country. BMC Public Health, 10, Article 286. https://doi.org/10.1186/1471-2458-10-286

Allen, J. J., \& Anderson, C. A. (2018). Satisfaction and frustration of basic psychological needs in the real world and in video games predict internet gaming disorder scores and well-being. Computers in Human Behavior, 84, $220-$ 229. https://doi.org/10.1016/j.chb.2018.02.034

American Psychiatric Association. (2013). Diagnostic and statistical manual of mental disorders: DSM-5 ${ }^{\mathrm{TM}}$ (5th ed.). American Psychiatric Publishing, Inc. https://doi.org/10.1176/appi.books.9780890425596

Aron, A., Aron, E. N., \& Smollan, D. (1992). Inclusion of Other in the Self Scale and the structure of interpersonal closeness. Journal of Personality and Social Psychology, 63(4), 596-612. https://doi.org/10.1037/0022-3514.63.4.596

Bessière, K., Seay, A. F., \& Kiesler, S. (2007). The ideal elf: Identity exploration in World of Warcraft. CyberPsychology \& Behavior, 10(4), 530-535. https://doi.org/10.1089/cpb.2007.9994

Billieux, J., Flayelle, M., Rumpf, H.-J., \& Stein, D. J. (2019). High involvement versus pathological involvement in video games: A crucial distinction for ensuring the validity and utility of gaming disorder. Current Addiction Reports, 6(3), 323-330. https://doi.org/10.1007/s40429-019-00259-x

Billieux, J., Schimmenti, A., Khazaal, Y., Maurage, P., \& Heeren, A. (2015). Are we overpathologizing everyday life? A tenable blueprint for behavioral addiction research. Journal of Behavioral Addictions, 4(3), 119-123. https://doi.org/10.1556/2006.4.2015.009

Billieux, J., Thorens, G., Khazaal, Y., Zullino, D. F., Achab, S., \& Van der Linden, M. (2015). Problematic involvement in online games: A cluster analytic approach. Computers in Human Behavior, 43, 242-250.

https://doi.org/10.1016/j.chb.2014.10.055

Blinka, L., \& Mikuška, J. (2014). The role of social motivation and sociability of gamers in online game addiction. Cyberpsychology: Journal of Psychosocial Research on Cyberspace, 8(2), Article 6. https://doi.org/10.5817/CP2014-2-6

Boyle, E. A., Connolly, T. M., Hainey, T., \& Boyle, J. M. (2012). Engagement in digital entertainment games: A systematic review. Computers in Human Behavior, 28(3), 771-780. https://doi.org/10.1016/j.chb.2011.11.020

Braghirolli, L. F., Ribeiro, J. L. D., Weise, A. D., \& Pizzolato, M. (2016). Benefits of educational games as an introductory activity in industrial engineering education. Computers in Human Behavior, 58, 315-324. https://doi.org/10.1016/j.chb.2015.12.063

Brunborg, G. S., Mentzoni, R. A., Melkevik, O. R., Torsheim, T., Samdal, O., Hetland, J., Schou Andreassen, C., \& Palleson, S. (2013). Gaming addiction, gaming engagement, and psychological health complaints among Norwegian adolescents. Media Psychology, 16(1), 115-128. https://doi.org/10.1080/15213269.2012.756374

Burleigh, T. L., Griffiths, M. D., Sumich, A., Stavropoulos, V., \& Kuss, D. J. (2019). A systematic review of the cooccurrence of gaming disorder and other potentially addictive behaviors. Current Addiction Reports, 6(4), 383-401. https://doi.org/10.1007/s40429-019-00279-7 
Byrne, B. M. (2012). Structural equation modeling with Mplus: Basic concepts, applications, and programming. Routledge.

Caplan, S., Williams, D., \& Yee, N. (2009). Problematic Internet use and psychosocial well-being among MMO players. Computers in Human Behavior, 25(6), 1312-1319. https://doi.org/10.1016/j.chb.2009.06.006

Charlton, J. P. (2002). A factor-analytic investigation of computer 'addiction' and engagement. British Journal of Psychology, 93(3), 329-344. https://doi.org/10.1348/000712602760146242

Charlton, J. P., \& Danforth, I. D. W. (2007). Distinguishing addiction and high engagement in the context of online game playing. Computers in Human Behavior, 23(3), 1531-1548. https://doi.org/10.1016/j.chb.2005.07.002

Charlton, J. P., \& Danforth, I. D. W. (2010). Validating the distinction between computer addiction and engagement: Online game playing and personality. Behaviour \& Information Technology, 29(6), 601-613. https://doi.org/10.1080/01449290903401978

Chen, F. F. (2007). Sensitivity of goodness of fit indexes to lack of measurement invariance. Structural Equation Modeling: A Multidisciplinary Journal, 14(3), 464-504. https://doi.org/10.1080/10705510701301834

Colwell, J., \& Payne, J. (2000). Negative correlates of computer game play in adolescents. British Journal of Psychology, 91(3), 295-310. https://doi.org/10.1348/000712600161844

Crocker, J., \& Wolfe, C. T. (2001). Contingencies of self-worth. Psychological Review, 108(3), 593-623. https://doi.org/10.1037/0033-295X.108.3.593

Deleuze, J., Maurage, P., Schimmenti, A., Nuyens, F., Melzer, A., \& Billieux, J. (2019). Escaping reality through videogames is linked to an implicit preference for virtual over real-life stimuli. Journal of Affective Disorders, 245, 1024-1031. https://doi.org/10.1016/j.jad.2018.11.078

Deleuze, J., Nuyens, F., Rochat, L., Rothen, S., Maurage, P., \& Billieux, J. (2017). Established risk factors for addiction fail to discriminate between healthy gamers and gamers endorsing DSM-5 Internet gaming disorder. Journal of Behavioral Addictions, 6(4), 516-524. https://doi.org/10.1556/2006.6.2017.074

Di Blasi, M., Giardina, A., Coco, G. L., Giordano, C., Billieux, J., \& Schimmenti, A. (2020). A compensatory model to understand dysfunctional personality traits in problematic gaming: The role of vulnerable narcissism. Personality and Individual Differences, 160, Article 109921. https://doi.org/10.1016/j.paid.2020.109921

Dobrescu, L. I., Greiner, B., \& Motta, A. (2015). Learning economics concepts through game-play: An experiment. International Journal of Educational Research, 69, 23-37. https://doi.org/10.1016/j.ijer.2014.08.005

Durkin, K., \& Barber, B. (2002). Not so doomed: Computer game play and positive adolescent development. Journal of Applied Developmental Psychology, 23(4), 373-392. https://doi.org/10.1016/S0193-3973(02)00124-7

Entertainment Software Association. (2020). 2020 essential facts about the video game industry. https://www.theesa.com/resource/2020-essential-facts/

Fling, S., Smith, L., Rodriguez, T., Thornton, D., Atkins, E., \& Nixon, K. (1992). Videogames, aggression, and selfesteem: A survey. Social Behavior and Personality: An International Journal, 20(1), 39-45.

https://doi.org/10.2224/sbp.1992.20.1.39

Funk, J. B., \& Buchman, D. D. (1996). Playing violent video and computer games and adolescent self-concept. Journal of Communication, 46(2), 19-32. https://doi.org/10.1111/j.1460-2466.1996.tb01472.x 
Fuster, H., Chamarro, A., Carbonell, X., \& Vallerand, R. J. (2014). Relationship between passion and motivation for gaming in players of massively multiplayer online role-playing games. Cyberpsychology, Behavior, and Social Networking, 17(5), 292-297. https://doi.org/10.1089/cyber.2013.0349

Gabbiadini, A., Mari, S., Volpato, C., \& Monaci, M. G. (2014). Identification processes in online groups: Identity motives in the virtual realm of MMORPGs. Journal of Media Psychology, 26(3), 141-152.

https://doi.org/10.1027/1864-1105/a000119

Graham, J. W. (2009). Missing data analysis: Making it work in the real world. Annual Review of Psychology, 60, 549576. https://doi.org/10.1146/annurev.psych.58.110405.085530

Granic, I., Lobel, A., \& Engels, R. C. M. E. (2014). The benefits of playing video games. American Psychologist, 69(1), 66-78. https://doi.org/10.1037/a0034857

Griffiths, M. D. (2004). Can videogames be good for your health? Journal of Health Psychology, 9(3), 339-344. https://doi.org/10.1177/1359105304042344

Griffiths, M. D. (2019). The therapeutic and health benefits of playing video games. In A. Attrill-Smith, C. Fullwood, M. Keep, \& D. J. Kuss (Eds.), The Oxford handbook of cyberpsychology (pp. 485-505). Oxford University Press.

Higgins, E. T. (1987). Self-discrepancy: A theory relating self and affect. Psychological Review, 94(3), 319-340. https://doi.org/10.1037/0033-295X.94.3.319

Hussain, Z., \& Griffiths, M. D. (2009). Excessive use of massively multi-player online role-playing games: A pilot study. International Journal of Mental Health and Addiction, 7(4), 563-571. https://doi.org/10.1007/s11469-0099202-8

Jeong, H., Yim, H. W., Lee, S.-Y., Lee, H. K., Potenza, M. N., Kwon, J.-H., Koo, H. J., Kweon, Y.-S., Bhang, S., \& Choi, J.S. (2018). Discordance between self-report and clinical diagnosis of Internet gaming disorder in adolescents. Scientific Reports, 8(1), Article 10084. https://doi.org/10.1038/s41598-018-28478-8

Jo, Y. S., Bhang, S. Y., Choi, J. S., Lee, H. K., Lee, S. Y., \& Kweon, Y.-S. (2019). Clinical characteristics of diagnosis for Internet Gaming Disorder: Comparison of DSM-5 IGD and ICD-11 GD diagnosis. Journal of Clinical Medicine, 8(7), Article 945. https://doi.org/10.3390/jcm8070945

Johnson, D., Jones, C., Scholes, L., \& Carras, M. C. (2013). Videogames and wellbeing: A comprehensive review. Young and Well Cooperative Research Centre.

Jones, C. M., Scholes, L., Johnson, D., Katsikitis, M., \& Carras, M. C. (2014). Gaming well: Links between videogames and flourishing mental health. Frontiers in Psychology, 5, Article 260.

https://doi.org/10.3389/fpsyg.2014.00260

Kaczmarek, L. D., \& Drążkowski, D. (2014). MMORPG escapism predicts decreased well-being: Examination of gaming time, game realism beliefs, and online social support for offline problems. Cyberpsychology, Behavior, and Social Networking, 17(5), 298-302. https://doi.org/10.1089/cyber.2013.0595

Kardefelt-Winther, D. (2014a). A conceptual and methodological critique of internet addiction research: Towards a model of compensatory internet use. Computers in Human Behavior, 31, 351-354.

https://doi.org/10.1016/j.chb.2013.10.059

Kardefelt-Winther, D. (2014b). The moderating role of psychosocial well-being on the relationship between escapism and excessive online gaming. Computers in Human Behavior, 38, 68-74.

https://doi.org/10.1016/j.chb.2014.05.020 
Kardefelt-Winther, D. (2015). Commentary on: Are we overpathologizing everyday life? A tenable blueprint for behavioral addiction research. Problems with atheoretical and confirmatory research approaches in the study of behavioral addictions. Journal of Behavioral Addictions, 4(3), 126-129. https://doi.org/10.1556/2006.4.2015.019

Kenny, D. A. (2015). Measuring model fit. http://davidakenny.net/cm/fit.htm

Kirby, A., Jones, C., \& Copello, A. (2014). The impact of massively multiplayer online role playing games (MMORPGs) on psychological wellbeing and the role of play motivations and problematic use. International Journal of Mental Health and Addiction, 12(1), 36-51. https://doi.org/10.1007/s11469-013-9467-9

Klimmt, C., Hefner, D., \& Vorderer, P. (2009). The video game experience as "true" identification: A theory of enjoyable alterations of players' self-perception. Communication Theory, 19(4), 351-373.

https://doi.org/10.1111/j.1468-2885.2009.01347.x

Lehenbauer-Baum, M., \& Fohringer, M. (2015). Towards classification criteria for internet gaming disorder: Debunking differences between addiction and high engagement in a German sample of World of Warcraft players. Computers in Human Behavior, 45, 345-351. https://doi.org/10.1016/j.chb.2014.11.098

Lehenbauer-Baum, M., Klaps, A., Kovacovsky, Z., Witzmann, K., Zahlbruckner, R., \& Stetina, B. U. (2015). Addiction and engagement: An explorative study toward classification criteria for internet gaming disorder. Cyberpsychology, Behavior, and Social Networking, 18(6), 343-349. https://doi.org/10.1089/cyber.2015.0063

Leménager, T., Gwodz, A., Richter, A., Reinhard, I., Kämmerer, N., Sell, M., \& Mann, K. (2013). Self-concept deficits in massively multiplayer online role-playing games addiction. European Addiction Research, 19(5), 227-234. https://doi.org/10.1159/000345458

Li, D., Liau, A., \& Khoo, A. (2011). Examining the influence of actual-ideal self-discrepancies, depression, and escapism, on pathological gaming among massively multiplayer online adolescent gamers. Cyberpsychology, Behavior, and Social Networking, 14(9), 535-539. https://doi.org/10.1089/cyber.2010.0463

Loftus, E. F., Klinger, M. R., Smith, K. D., \& Fiedler, J. (1990). A tale of two questions: Benefits of asking more than one question. Public Opinion Quarterly, 54(3), 330-345. https://doi.org/https://doi.org/10.1086/269210

Mancini, T., Imperato, C., \& Sibilla, F. (2019). Does avatar's character and emotional bond expose to gaming addiction? Two studies on virtual self-discrepancy, avatar identification and gaming addiction in massively multiplayer online role-playing game players. Computers in Human Behavior, 92, 297-305.

https://doi.org/10.1016/j.chb.2018.11.007

Mancini, T., \& Sibilla, F. (2017). Offline personality and avatar customisation. Discrepancy profiles and avatar identification in a sample of MMORPG players. Computers in Human Behavior, 69, 275-283.

https://doi.org/10.1016/j.chb.2016.12.031

Männikkö, N., Ruotsalainen, H., Miettunen, J., Pontes, H. M., \& Kääriäinen, M. (2017). Problematic gaming behaviour and health-related outcomes: A systematic review and meta-analysis. Journal of Health Psychology, 25(1), 67-81. https://doi.org/10.1177/1359105317740414

Mills, D. J., Milyavskaya, M., Mettler, J., \& Heath, N. L. (2018). Exploring the pull and push underlying problem video game use: A self-determination theory approach. Personality and Individual Differences, 135, 176-181. https://doi.org/10.1016/j.paid.2018.07.007

Morris, L. S., \& Voon, V. (2016). Dimensionality of cognitions in behavioral addiction. Current Behavioral Neuroscience Reports, 3(1), 49-57. https://doi.org/10.1007/s40473-016-0068-3 
Musetti, A., \& Corsano, P. (2018). The internet is not a tool: Reappraising the model for internet-addiction disorder based on the constraints and opportunities of the digital environment. Frontiers in Psychology, 9, Article 558. https://doi.org/10.3389/fpsyg.2018.00558

Musetti, A., Mancini, T., Corsano, P., Santoro, G., Cavallini, M. C., \& Schimmenti, A. (2019). Maladaptive personality functioning and psychopathological symptoms in problematic video game players: A person-centered approach. Frontiers in Psychology, 10, Article 2559. https://doi.org/10.3389/fpsyg.2019.02559

Muthén, L. K., \& Muthén, B. O. (1998-2012). MPlus user's guide (7th ed.). Muthén \& Muthén.

Peters, C. S., \& Malesky, L. A., Jr. (2008). Problematic usage among highly-engaged players of massively multiplayer online role playing games. CyberPsychology and Behavior, 11(4), 481-484.

https://doi.org/10.1089/cpb.2007.0140

Peterson, C., Park, N., \& Seligman, M. E. P. (2005). Orientations to happiness and life satisfaction: The full life versus the empty life. Journal of Happiness Studies, 6(1), 25-41. https://doi.org/10.1007/s10902-004-1278-z

Przybylski, A. K., \& Weinstein, N. (2019). Investigating the motivational and psychosocial dynamics of dysregulated gaming: Evidence from a preregistered cohort study. Clinical Psychological Science, 7(6), 1257-1265. https://doi.org/10.1177/2167702619859341

Przybylski, A. K., Weinstein, N., Murayama, K., Lynch, M. F., \& Ryan, R. M. (2012). The ideal self at play: The appeal of video games that let you be all you can be. Psychological Science, 23(1), 69-76.

https://doi.org/10.1177/0956797611418676

Przybylski, A. K., Weinstein, N., Ryan, R. M., \& Rigby, C. S. (2009). Having to versus wanting to play: Background and consequences of harmonious versus obsessive engagement in video games. CyberPsychology \& Behavior, 12(5), 485-492. https://doi.org/10.1089/cpb.2009.0083

Riva, G., Baños, R. M., Botella, C., Wiederhold, B. K., \& Gaggioli, A. (2012). Positive technology: Using interactive technologies to promote positive functioning. Cyberpsychology, Behavior, and Social Networking, 15(2), 69-77. https://doi.org/10.1089/cyber.2011.0139

Rosenberg, M. (1979). Conceiving the self. Basic Books.

Ryan, R. M., \& Deci, E. L. (2000). Self-determination theory and the facilitation of intrinsic motivation, social development, and well-being. American Psychologist, 55(1), 68-78. https://doi.org/10.1037/0003-066X.55.1.68

Ryan, R. M., \& Deci, E. L. (2001). On happiness and human potentials: A review of research on hedonic and eudaimonic well-being. Annual Review of Psychology, 52(1), 141-166.

https://doi.org/10.1146/annurev.psych.52.1.141

Ryan, R. M., Rigby, C. S., \& Przybylski, A. (2006). The motivational pull of video games: A self-determination theory approach. Motivation and Emotion, 30(4), 344-360. https://doi.org/10.1007/s11031-006-9051-8

Ryff, C. D. (2014). Self-realisation and meaning making in the face of adversity: A eudaimonic approach to human resilience. Journal of Psychology in Africa, 24(1), 1-12. https://doi.org/10.1080/14330237.2014.904098

Satorra, A., \& Bentler, P. M. (2001). A scaled difference chi-square test statistic for moment structure analysis. Psychometrika, 66(4), 507-514. https://doi.org/10.1007/BF02296192

Schimmenti, A., \& Caretti, V. (2010). Psychic retreats or psychic pits?: Unbearable states of mind and technological addiction. Psychoanalytic Psychology, 27(2), 115-132. https://doi.org/10.1037/a0019414 
Schimmenti, A., Guglielmucci, F., Barbasio, C., \& Granieri, A. (2012). Attachment disorganization and dissociation in virtual worlds: A study on problematic Internet use among players of online role playing games. Clinical Neuropsychiatry: Journal of Treatment Evaluation, 9(5), 195-202.

Schueller, S. M., \& Seligman, M. E. P. (2010). Pursuit of pleasure, engagement, and meaning: Relationships to subjective and objective measures of well-being. The Journal of Positive Psychology, 5(4), 253-263.

https://doi.org/10.1080/17439761003794130

Scorsolini-Comin, F., Fontaine, A. M. G. V., Koller, S. H., \& dos Santos, M. A. (2013). From authentic happiness to well-being: The flourishing of positive psychology. Psicologia: Reflexão e Crítica, 26(4), 663-670.

https://doi.org/10.1590/S0102-79722013000400006

Seligman, M. E. P. (2002). Authentic happiness: Using the new positive psychology to realize your potential for lasting fulfillment. Free Press.

Sibilla, F. (2019). Implicazioni psicosociali dell'uso dei massively multiplayer online role-playing games: II rapporto tra le modalità di gioco, il sé e il benessere [Psychosocial implications of Massively Multiplayer Online RolePlaying Games: The relationship between the game usage, the self, and the well-being; Doctoral thesis, University of Parma, Italy]. https://hdl.handle.net/1889/3762

Sibilla, F., \& Mancini, T. (2018). I am (not) my avatar: A review of the user-avatar relationships in Massively Multiplayer Online Worlds. Cyberpsychology: Journal of Psychosocial Research on Cyberspace, 12(3), Article 4. https://doi.org/10.5817/CP2018-3-4

Slater, M., \& Usoh, M. (1993). Representations systems, perceptual position, and presence in immersive virtual environments. Presence: Teleoperators \& Virtual Environments, 2(3), 221-233.

https://doi.org/10.1162/pres.1993.2.3.221

Smahel, D., Blinka, L., \& Ledabyl, O. (2008). Playing MMORPGs: Connections between addiction and identifying with a character. CyberPsychology \& Behavior, 11(6), 715-718. https://doi.org/10.1089/cpb.2007.0210

Smyth, J. M. (2007). Beyond self-selection in video game play: An experimental examination of the consequences of massively multiplayer online role-playing game play. CyberPsychology and Behavior, 10(5), 717-721.

https://doi.org/10.1089/cpb.2007.9963

Snodgrass, J. G., Dengah, H. J. F., Il., Lacy, M. G., \& Fagan, J. (2013). A formal anthropological view of motivation models of problematic MMO play: Achievement, social, and immersion factors in the context of culture. Transcultural Psychiatry, 50(2), 235-262. https://doi.org/10.1177/1363461513487666

Snodgrass, J. G., Lacy, M. G., Dengah, H. J. F., Il., \& Fagan, J. (2011). Cultural consonance and mental wellness in the World of Warcraft: Online games as cognitive technologies of 'absorption-immersion'. Cognitive Technology, 16(1), 11-23.

Statista. (2020). Online Games - Worldwide. https://www.statista.com/outlook/212/100/online-games/worldwide

Stavropoulos, V., Burleigh, T. L., Beard, C. L., Gomez, R., \& Griffiths, M. D. (2019). Being there: A preliminary study examining the role of presence in internet gaming disorder. International Journal of Mental Health and Addiction, 17(4), 880-890. https://doi.org/10.1007/s11469-018-9891-y

Stetina, B. U., Kothgassner, O. D., Lehenbauer, M., \& Kryspin-Exner, I. (2011). Beyond the fascination of onlinegames: Probing addictive behavior and depression in the world of online-gaming. Computers in Human Behavior, 27(1), 473-479. https://doi.org/10.1016/j.chb.2010.09.015 
Vallerand, R. J., Blanchard, C., Mageau, G. A., Koestner, R., Ratelle, C., Léonard, M., Gagné, M., \& Marsolais, J. (2003). Les passions de l'âme: On obsessive and harmonious passion. Journal of Personality and Social Psychology, 85(4), 756-767. https://doi.org/10.1037/0022-3514.85.4.756

Van Rooij, A. J., Ferguson, C. J., Carras, M. C., Kardefelt-Winther, D., Shi, J. Z., Aarseth, E., Bean, A. M., Helmersson Bergmark, K., Brus, A., Coulson, M., Deleuze, J., Dullur, P., Dunkels, E., Edman, J., Elson, M., Etchells, P. J., Fiskaali, A., Granic, I., Jansz, J., . . Przybylski, A. K. (2018). A weak scientific basis for gaming disorder: Let us err on the side of caution. Journal of Behavioral Addictions, 7(1), 1-9. https://doi.org/10.1556/2006.7.2018.19

Wack, E., \& Tantleff-Dunn, S. (2009). Relationships between electronic game play, obesity, and psychosocial functioning in young men. CyberPsychology \& Behavior, 12(2), 241-244. https://doi.org/10.1089/cpb.2008.0151

Wang, E. S.-T., Chen, L. S.-L., Lin, J. Y.-C., \& Wang, M. C.-H. (2008). The relationship between leisure satisfaction and life satisfaction of adolescents concerning online games. Adolescence, 43(169), 177-184.

World Health Organization. (2018, September 14). Addictive behaviours: Gaming disorder. https://www.who.int/news-room/q-a-detail/addictive-behaviours-gaming-disorder

World Medical Association. (2013). World Medical Association Declaration of Helsinki: Ethical principles for medical research involving human subjects. JAMA, 310(20), 2191-2194.

https://doi.org/10.1001/jama.2013.281053

Yee, N. (2006). The demographics, motivations and derived experiences of users of massively-multiuser online graphical environments. PRESENCE: Teleoperators and Virtual Environments, 15(3), 309-329.

https://doi.org/10.1162/pres.15.3.309

You, S., Kim, E., \& Lee, D. (2017). Virtually real: Exploring avatar identification in game addiction among massively multiplayer online role-playing games (MMORPG) players. Games and Culture, 12(1), 56-71.

https://doi.org/10.1177/1555412015581087 


\section{Supplementary Material}

Table S1. Standardized Estimates of Effects of Meaningful Life Model (M1.1).

\begin{tabular}{|c|c|c|c|c|}
\hline & $B$ & SE & $Z$ & $95 \% \mathrm{Cl}$ \\
\hline \multicolumn{5}{|l|}{ Obst2 on } \\
\hline $\mathrm{Har}_{\mathrm{t} 1}$ & .069 & .063 & 1.105 & {$[-.054, .192]$} \\
\hline Obst1 & .570 & .080 & $7.122^{\star \star \star}$ & {$[.413, .727]$} \\
\hline Est 1 & -.056 & .075 & -0.745 & {$[-.202, .091]$} \\
\hline Meat1 & -.192 & .070 & $-2.744^{\star *}$ & {$[-.330,-.055]$} \\
\hline \multicolumn{5}{|l|}{ Obst3 on } \\
\hline $\mathrm{Har}_{\mathrm{t} 2}$ & .126 & .069 & 1.832 & {$[-.009, .261]$} \\
\hline Obst1 & .294 & .098 & $3.008^{* *}$ & {$[.103, .486]$} \\
\hline Obst2 & .391 & .110 & $3.552^{\star * *}$ & {$[.175, .607]$} \\
\hline Estt2 & -.162 & .074 & $-2.189^{*}$ & {$[-.308,-.017]$} \\
\hline Meat2 & -.044 & .065 & -0.685 & {$[-.171, .082]$} \\
\hline \multicolumn{5}{|l|}{$\mathrm{Har}_{\mathrm{t} 2}$ on } \\
\hline Hart1 & .729 & .046 & $15.781^{* \star *}$ & {$[.639, .820]$} \\
\hline Obst1 & .130 & .065 & $2.003^{*}$ & {$[.003, .257]$} \\
\hline Est $1_{1}$ & -.074 & .064 & -1.166 & {$[-.199, .050]$} \\
\hline Meat1 & .066 & .058 & 1.143 & {$[-.047, .180]$} \\
\hline \multicolumn{5}{|l|}{$\mathrm{Har}_{\mathrm{t} 3}$ on } \\
\hline $\mathrm{Har}_{\mathrm{t} 1}$ & .214 & .069 & $3.108^{\star *}$ & {$[.079, .349]$} \\
\hline Hart2 & .681 & .060 & $11.432^{\star * *}$ & {$[.564, .798]$} \\
\hline Obst2 & .016 & .039 & 0.396 & {$[-.061, .093]$} \\
\hline Estt2 & .061 & .051 & 1.177 & {$[-.040, .161]$} \\
\hline Meat2 & .012 & .055 & 0.227 & {$[-.095, .120]$} \\
\hline \multicolumn{5}{|l|}{ Estt2 on } \\
\hline $\mathrm{Har}_{\mathrm{t} 1}$ & -.030 & .040 & -0.742 & {$[-.108, .049]$} \\
\hline Obst1 & -.020 & .043 & -0.460 & {$[-.103, .064]$} \\
\hline Estt1 & .784 & .042 & $18.836^{* * *}$ & {$[.702, .865]$} \\
\hline Meat1 & .100 & .053 & 1.893 & {$[-.004, .203]$} \\
\hline \multicolumn{5}{|l|}{ Est t3 on } \\
\hline $\mathrm{Har}_{\mathrm{t} 2}$ & -.025 & .038 & -0.660 & {$[-.098, .049]$} \\
\hline Obst2 & .000 & .039 & -0.012 & {$[-.076, .075]$} \\
\hline Estt1 & .397 & .101 & $3.927^{\star * *}$ & {$[.199, .595]$} \\
\hline Estt2 & .487 & .107 & $4.546^{\star * *}$ & {$[.277, .697]$} \\
\hline Meat2 & .063 & .043 & 1.453 & {$[-.022, .148]$} \\
\hline \multicolumn{5}{|l|}{ Meat2 on } \\
\hline $\mathrm{Har}_{\mathrm{t} 1}$ & -.048 & .053 & -0.902 & {$[-.152, .056]$} \\
\hline Obst1 & -.003 & .044 & -0.069 & {$[-.089, .083]$} \\
\hline Est 1 & .027 & .050 & 0.532 & {$[-.072, .126]$} \\
\hline Meat1 & .811 & .037 & $21.965^{* \star *}$ & {$[.739, .884]$} \\
\hline \multicolumn{5}{|l|}{ Meat3 on } \\
\hline $\mathrm{Har}_{\mathrm{t} 2}$ & -.018 & .030 & -0.585 & {$[-.077, .042]$} \\
\hline Obst2 & -.027 & .030 & -0.898 & {$[-.086, .032]$} \\
\hline Estt2 & .027 & .048 & 0.568 & {$[-.066, .120]$} \\
\hline Meat1 & .318 & .072 & $4.416^{* * *}$ & {$[.177, .459]$} \\
\hline Meat2 & .620 & .074 & $8.374^{\star * *}$ & {$[.475, .765]$} \\
\hline
\end{tabular}




\begin{tabular}{|c|c|c|c|c|}
\hline \multicolumn{5}{|l|}{ Obst1 on } \\
\hline $\mathrm{Har}_{\mathrm{t} 1}$ & .000 & .000 & 999.000 & {$[.000, .000]$} \\
\hline Estt1 & -.151 & .088 & -1.711 & {$[-.324, .022]$} \\
\hline Meat1 & -.190 & .096 & $-1.982^{*}$ & {$[-.377,-.002]$} \\
\hline \multicolumn{5}{|l|}{ Hart1 on } \\
\hline Estt1 & -.043 & .076 & -0.564 & {$[-.192, .106]$} \\
\hline Meat1 & .089 & .083 & 1.075 & {$[-.073, .251]$} \\
\hline \multicolumn{5}{|l|}{ Est ${ }_{11}$ on } \\
\hline Meat1 & .506 & .064 & $7.941^{* * *}$ & {$[.381, .630]$} \\
\hline \multicolumn{5}{|l|}{ Obst2 on } \\
\hline $\mathrm{Har}_{\mathrm{t} 2}$ & .000 & .000 & 999.000 & {$[.000, .000]$} \\
\hline Estt2 & .039 & .082 & 0.468 & {$[-.123, .200]$} \\
\hline Meat2 & .025 & .074 & 0.337 & {$[-.119, .169]$} \\
\hline \multicolumn{5}{|l|}{$\mathrm{Har}_{\mathrm{t} 2}$ on } \\
\hline Estt2 & -.032 & .087 & -0.365 & {$[-.202, .139]$} \\
\hline Meat2 & .091 & .066 & 1.376 & {$[-.039, .221]$} \\
\hline \multicolumn{5}{|l|}{ Estt2 on } \\
\hline Meat2 & .099 & .085 & 1.171 & {$[-.067, .266]$} \\
\hline \multicolumn{5}{|l|}{ Obst3 on } \\
\hline Hart3 & .000 & .000 & 999.000 & {$[.000, .000]$} \\
\hline Estt3 & .096 & .076 & 1.264 & {$[-.053, .245]$} \\
\hline Meat3 & .028 & .080 & 0.349 & {$[-.129, .185]$} \\
\hline \multicolumn{5}{|l|}{ Hart3 on } \\
\hline Estt3 & .086 & .074 & 1.156 & {$[-.060, .231]$} \\
\hline Meat3 & .022 & .101 & 0.214 & {$[-.177, .220]$} \\
\hline \multicolumn{5}{|l|}{ Est t3 on } \\
\hline Meat3 & .199 & .078 & $2.558^{\star *}$ & {$[.047, .352]$} \\
\hline
\end{tabular}

Table S2. Standardized Estimates of Effects of Engaged Life Model (M2.1).

\begin{tabular}{|c|c|c|c|c|}
\hline & $B$ & SE & $Z$ & $95 \% \mathrm{Cl}$ \\
\hline \multicolumn{5}{|l|}{ Obst2 on } \\
\hline $\mathrm{Har}_{\mathrm{t} 1}$ & .035 & .067 & 0.522 & {$[-.097, .167]$} \\
\hline Obst1 & .580 & .083 & $6.990^{\star \star \star}$ & {$[.417, .742]$} \\
\hline Estt1 & -.147 & .070 & $-2.109^{*}$ & {$[-.283,-.010]$} \\
\hline Engt1 & .044 & .073 & 0.609 & {$[-.099, .188]$} \\
\hline \multicolumn{5}{|l|}{ Obst3 on } \\
\hline Hart2 $_{\text {t2 }}$ & .104 & .072 & 1.447 & {$[-.037, .245]$} \\
\hline Obst1 & .284 & .097 & $2.924^{\star \star}$ & {$[.094, .474]$} \\
\hline Obst2 & .389 & .109 & $3.573^{\star \star \star}$ & {$[.176, .603]$} \\
\hline Estt2 & -.188 & .076 & $-2.456^{* *}$ & {$[-.338,-.038]$} \\
\hline Engt2 & .059 & .056 & 1.041 & {$[-.052, .169]$} \\
\hline \multicolumn{5}{|l|}{ Hart2 on } \\
\hline Hart1 $_{\text {t }}$ & .710 & .049 & $14.537^{\star \star \star}$ & {$[.614, .805]$} \\
\hline Obst1 & .096 & .067 & 1.430 & {$[-.035, .226]$} \\
\hline Estt1 & -.033 & .060 & -0.555 & {$[-.152, .085]$} \\
\hline Engt1 $_{\mathrm{t}}$ & .092 & .058 & 1.585 & {$[-.022, .206]$} \\
\hline
\end{tabular}




\begin{tabular}{ccccc}
\hline Hart3 on & & & & \\
Hart1 & .216 & .070 & $3.099^{\star *}$ & {$[.079, .352]$} \\
Hart2 & .668 & .060 & $11.114^{* * *}$ & {$[.551, .786]$} \\
Obst2 & .002 & .042 & 0.057 & {$[-.080, .085]$} \\
Est ${ }_{22}$ & .062 & .049 & 1.262 & {$[-.034, .158]$} \\
Engt2 & .039 & .050 & 0.771 & {$[-.060, .137]$}
\end{tabular}

Estt2 on

$\begin{array}{ccccc}\text { Hart1 }_{\mathrm{t}} & -.028 & .043 & -0.657 & {[-.112, .056]} \\ \text { Obst1 }_{\mathrm{t}} & -.040 & .046 & -0.882 & {[-.130, .049]} \\ \text { Est }_{\mathrm{t} 1} & .836 & .027 & 31.073^{* * *} & {[.783, .888]} \\ \text { Eng }_{\mathrm{t} 1} & .031 & .049 & 0.638 & {[-.065, .128]}\end{array}$

Estt3 on

$\left.\begin{array}{llll}\text { Hart2 } & -.008 & .041 & -0.184\end{array}\right][-.089, .073]$

$\left.\begin{array}{lllll}\text { Obst2 } & -.003 & .041 & -0.061 \quad[-.083, .078\end{array}\right]$

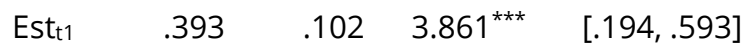

$\begin{array}{lllll}\text { Est } & .522 & .101 & 5.151^{* * *} & {[.324, .721]}\end{array}$

$\begin{array}{lllll}\text { Engt2 }_{\mathrm{n}} & -.034 & .052 & -0.654 & {[-.135, .067]}\end{array}$

Engt2 on

$\begin{array}{llll}\text { Hart }_{\mathrm{t}} & .097 \quad .067 \quad 1.450 \quad[-.034, .228]\end{array}$

$\begin{array}{lllll}\text { Obst1 } & .118 & .057 & 2.075 * \quad[.007, .230]\end{array}$

$\begin{array}{lllll}\text { Est }_{\mathrm{t} 1} & .099 & .057 & 1.727 & {[-.013, .210}\end{array}$

$\begin{array}{lllll}\text { Eng }_{\mathrm{t} 1} & .629 & .049 & 12.748^{* * *} & {[.532, .726}\end{array}$

Engt3 on

Hart2 $\quad .063 \quad .051 \quad 1.243 \quad[-.036, .163]$

$\begin{array}{lllll}\text { Obst2 } & .049 & .053 & 0.930 \quad[-.054, .152]\end{array}$

$\begin{array}{lllll}\text { Est } 2 & -.004 & .063 & -0.059 & {[-.127, .120]}\end{array}$

$\begin{array}{lllll}\text { Engt } 1 & .130 & .066 & 1.959^{*} & {[.000, .260]}\end{array}$

$\begin{array}{lllll}\text { Engt2 } & .653 & .068 & 9.662^{* * *} & {[.520, .785]}\end{array}$

Obst1 on

$\begin{array}{lllll}\text { Hart1 } & .000 \quad .000 \quad 999.000 & {[.000, .000}\end{array}$

$\begin{array}{lllll}\text { Est }_{\mathrm{t} 1} & -.151 & .088 & -1.711 \quad[-.324, .022]\end{array}$

$\left.\begin{array}{lllll}\text { Engt1 }_{\mathrm{t}} & .302 & .070 & 4.346^{* * *} & {[.166, .439}\end{array}\right]$

Hart 1 on

$\begin{array}{lllll}\text { Est }_{1} & -.043 \quad .076 & -0.564 \quad[-.192, .106]\end{array}$

$\begin{array}{lllll}\text { Engt1 }_{\mathrm{t}} & .297 & .074 & 4.030^{\star * *} & {[.153, .442]}\end{array}$

Estt1 on

$\begin{array}{lllll}\text { Engt1 }_{\mathrm{t}} & -.142 & .087 & -1.628 & {[-.314, .029]}\end{array}$

Obst2 on

$\left.\begin{array}{lllll}\text { Hart2 } & .000 \quad .000 & 999.000 & {[.000, .000}\end{array}\right]$

$\begin{array}{lllll}\text { Est } 2 & .000 & .087 & 0.003 & {[-.171, .171]}\end{array}$

$\begin{array}{lllll}\text { Engt2 } & .105 & .083 & 1.260 \quad[-.058, .268]\end{array}$

$\mathrm{Har}_{\mathrm{t} 2}$ on

$\begin{array}{lllll}\text { Est } 2 & -.034 & .090 & -0.373 \quad[-.210, .143]\end{array}$

$\begin{array}{lllll}\text { Engt2 } & .098 & .06 & 0.921 & {[-.110, .306}\end{array}$

Estt2 on

$\left.\begin{array}{lllll}\text { Engt2 } & .057 & .092 & 0.613 & {[-.125, .238}\end{array}\right]$

Obst3 on

$\left.\begin{array}{lllll}\text { Hart3 }_{\mathrm{H}} & .000 & .000 & 999.000 & {[.000, .000}\end{array}\right]$ 


\begin{tabular}{rllll}
\hline Estt3 & .097 & .078 & 1.255 & {$[-.055, .249]$} \\
Engt3 & .036 & .096 & 0.375 & {$[-.153, .225]$} \\
Hart3 on & & & & \\
Est 33 & .093 & .071 & 1.303 & {$[-.047, .233]$} \\
Engt3 & .065 & .082 & 0.791 & {$[-.096, .227]$} \\
Estt3 on & & & & \\
Engt3 & .214 & .081 & $2.656^{* *}$ & {$[.056, .372]$} \\
\hline
\end{tabular}

Note. ${ }^{\star} p \leq .05,{ }^{* \star} p \leq .01,{ }^{* \star \star} p \leq .001$.

Table S3. Standardized Estimates of Effects of Pleasant Life Model (M3.3).

\begin{tabular}{|c|c|c|c|c|}
\hline & $B$ & $S E$ & $Z$ & $95 \% \mathrm{Cl}$ \\
\hline \multicolumn{5}{|l|}{ Obst2 on } \\
\hline Hart1 & .054 & .062 & 0.873 & {$[-.068, .176]$} \\
\hline Obst1 & .604 & .081 & $7.472^{* * *}$ & {$[.445, .762]$} \\
\hline Estt1 & -.147 & .068 & $-2.169^{*}$ & {$[-.280,-.014]$} \\
\hline $\mathrm{Ple}_{\mathrm{t} 1}$ & -.038 & .069 & -0.546 & {$[-.173, .098]$} \\
\hline \multicolumn{5}{|l|}{ Obst3 on } \\
\hline Hart2 & .129 & .066 & $1.952^{*}$ & {$[-.001, .258]$} \\
\hline Obst1 & .299 & .100 & $2.994^{\star *}$ & {$[.103, .494]$} \\
\hline Obst2 & .404 & .107 & $3.775^{* * *}$ & {$[.194, .613]$} \\
\hline Estt2 & -.182 & .072 & $-2.518^{\star *}$ & {$[-.323,-.040]$} \\
\hline $\mathrm{Ple}_{\mathrm{t} 2}$ & -.020 & .075 & -0.264 & {$[-.166, .126]$} \\
\hline \multicolumn{5}{|l|}{$\mathrm{Har}_{\mathrm{t} 2}$ on } \\
\hline Hart1 $_{\mathrm{t}}$ & .732 & .045 & $16.122^{\star \star *}$ & {$[.643, .821]$} \\
\hline Obst1 & .120 & .064 & 1.882 & {$[-.005, .246]$} \\
\hline Estt1 & -.049 & .061 & -0.809 & {$[-.168, .070]$} \\
\hline Plet1 $_{t}$ & .053 & .049 & 1.068 & {$[-.044, .149]$} \\
\hline \multicolumn{5}{|l|}{$\mathrm{Har}_{\mathrm{t} 3}$ on } \\
\hline $\operatorname{Har}_{\mathrm{t} 1}$ & .210 & .070 & $3.011^{* *}$ & {$[.073, .347]$} \\
\hline Hart2 & .683 & .058 & $11.768^{\star \star \star}$ & {$[.569, .797]$} \\
\hline Obst2 & .014 & .039 & 0.356 & {$[-.062, .089]$} \\
\hline Estt2 & .068 & .048 & 1.422 & {$[-.026, .163]$} \\
\hline $\mathrm{Ple}_{\mathrm{t} 2}$ & -.016 & .050 & -0.331 & {$[-.114, .081]$} \\
\hline \multicolumn{5}{|l|}{ Estt2 on } \\
\hline Hart1 $_{\text {t1 }}$ & -.019 & .040 & -0.466 & {$[-.098, .060]$} \\
\hline Obst1 & -.031 & .045 & -0.701 & {$[-.119, .056]$} \\
\hline Estt1 & .835 & .028 & $29.560^{\star \star *}$ & {$[.779, .890]$} \\
\hline $\mathrm{Ple}_{\mathrm{t} 1}$ & .000 & .041 & 0.008 & {$[-.080, .081]$} \\
\hline \multicolumn{5}{|l|}{ Estt3 on } \\
\hline Hart2 & -.026 & .038 & -0.684 & {$[-.100, .048]$} \\
\hline Obst2 & -.012 & .038 & -0.323 & {$[-.086, .061]$} \\
\hline Estt1 & .402 & .102 & $3.920^{* * *}$ & {$[.201, .603]$} \\
\hline Estt2 & .511 & .105 & $4.865^{\star \star \star}$ & {$[.305, .716]$} \\
\hline $\mathrm{Ple}_{\mathrm{t} 2}$ & .028 & .039 & 0.722 & {$[-.048, .104]$} \\
\hline \multicolumn{5}{|l|}{ Plet2 on } \\
\hline $\operatorname{Har}_{\mathrm{t} 1}$ & .082 & .054 & 1.524 & {$[-.023, .187]$} \\
\hline Obst1 & .040 & .055 & 0.724 & {$[-.069, .149]$} \\
\hline
\end{tabular}




\begin{tabular}{|c|c|c|c|c|}
\hline Estt1 & .086 & .057 & 1.501 & {$[-.026, .198]$} \\
\hline $\mathrm{Ple}_{\mathrm{t} 1}$ & .718 & .043 & $16.699^{* \star *}$ & {$[.634, .803]$} \\
\hline \multicolumn{5}{|l|}{$\mathrm{Ple}_{\mathrm{t} 3}$ on } \\
\hline Hart2 $_{\text {t2 }}$ & .059 & .058 & 1.004 & {$[-.056, .173]$} \\
\hline Obst2 & .109 & .092 & 1.193 & {$[-.070, .289]$} \\
\hline Estt2 & -.004 & .057 & -0.073 & {$[-.116, .108]$} \\
\hline Plet1 & .263 & .069 & $3.828^{* * *}$ & {$[.129, .398]$} \\
\hline $\mathrm{Ple}_{\mathrm{t} 2}$ & .557 & .065 & $8.540^{* * *}$ & {$[.429, .685]$} \\
\hline \multicolumn{5}{|l|}{ Obst1 on } \\
\hline $\mathrm{Har}_{\mathrm{t} 1}$ & .000 & .000 & 999.000 & {$[.000, .000]$} \\
\hline$E s t_{t 1}$ & .007 & .018 & 0.373 & {$[-.029, .042]$} \\
\hline Plet1 & .014 & .024 & 0.590 & {$[-.033, .061]$} \\
\hline \multicolumn{5}{|l|}{ Hart1 on } \\
\hline$E s t_{t 1}$ & .006 & .015 & 0.389 & {$[-.024, .036]$} \\
\hline$P_{e} 1$ & .062 & .019 & $3.195^{\star \star \star}$ & {$[.024, .100]$} \\
\hline \multicolumn{5}{|l|}{ Est ${ }_{t 1}$ on } \\
\hline Plet1 & .023 & .019 & 1.217 & {$[-.014, .061]$} \\
\hline \multicolumn{5}{|l|}{ Obst2 on } \\
\hline $\mathrm{Har}_{\mathrm{t} 2}$ & .000 & .000 & 999.000 & {$[.000, .000]$} \\
\hline Estt2 & .018 & .047 & 0.372 & {$[-.075, .110]$} \\
\hline $\mathrm{Ple}_{\mathrm{t} 2}$ & .028 & .046 & 0.602 & {$[-.062, .118]$} \\
\hline \multicolumn{5}{|l|}{$\mathrm{Har}_{\mathrm{t} 2}$ on } \\
\hline Estt2 & .018 & .046 & 0.392 & {$[-.072, .109]$} \\
\hline Plet2 & .142 & .042 & $3.349^{* \star *}$ & {$[.059, .225]$} \\
\hline \multicolumn{5}{|l|}{ Estt2 on } \\
\hline $\mathrm{Ple}_{\mathrm{t} 2}$ & .071 & .059 & 1.189 & {$[-.046, .187]$} \\
\hline \multicolumn{5}{|l|}{ Obst3 on } \\
\hline Hart3 & .000 & .000 & 999.000 & {$[.000, .000]$} \\
\hline Estt3 & .022 & .060 & 0.372 & {$[-.095, .139]$} \\
\hline Plet3 & .033 & .055 & 0.603 & {$[-.075, .141]$} \\
\hline \multicolumn{5}{|l|}{$\mathrm{Har}_{\mathrm{t} 3}$ on } \\
\hline Estt3 & .026 & .067 & 0.387 & {$[-.105, .157]$} \\
\hline $\mathrm{Ple}_{\mathrm{t} 3}$ & .193 & .057 & $3.392^{* \star *}$ & {$[.081, .304]$} \\
\hline \multicolumn{5}{|l|}{ Estt3 on } \\
\hline Plet3 & .089 & .074 & 1.200 & {$[-.056, .234]$} \\
\hline
\end{tabular}




\section{Correspondence to:}

Federica Sibilla

University of Parma - Department of Humanities, Social Sciences and Cultural Industries

Borgo Carissimi 10

Parma (PR), 43121

Italy

Email: federica.sibilla(at)unipr.it

Editorial record: First submission received on July 17, 2020. Revisions received on February 8, 2021 and April 15, 2021. Accepted for publication on May 31, 2021.

Editor in charge: David Smahel

\section{About Authors}

Federica Sibilla, Ph.D. (federica.sibilla@unipr.it) is a postdoctoral researcher in the Department of Humanities, Social Sciences and Cultural Industries at the University of Parma, Italy. Her research interests include the psychological processes and implications related to the use of video games, especially regarding identity, social relationships, and well-being.

Alessandro Musetti, Ph.D. (alessandro.musetti@unipr.it) is a research fellow of Dynamic Psychology at the Department of Humanities, Social Sciences and Cultural Industries, University of Parma, Italy. His primary research interests include psychodynamics of addictive behaviors and separation and individuation process in adolescence.

Tiziana Mancini (tiziana.mancini@unipr.it) is Associate Professor in Social Psychology and member of CIRS (Interdepartmental Center for Social Research) at the University of Parma. Her research is mainly focused on digital communication and migration studies.

(C) Author(s). The articles in Cyberpsychology: Journal of Psychosocial Research on Cyberspace are open access articles licensed under the terms of the Creative Commons BY-NC-ND 4.0 International License which permits unrestricted, non-commercial use, distribution and reproduction in any medium, provided the work is properly cited. 